\title{
Cohort at risk: long-term consequences of conflict for child school achievement
}

\section{Hendrik Jürges ${ }^{1}$ - Luca Stella ${ }^{2}$ (1) . Sameh Hallaq ${ }^{3,4}$. Alexandra Schwarz ${ }^{5}$}

Received: 21 March 2019 / Accepted: 6 July 2020 / Published online: 14 August 2020

(C) The Author(s) 2020

\begin{abstract}
We investigate the long-term effects of households' exposure to violent conflict on children's educational attainment in primary school, studying cognitive and noncognitive skills as possible causal channels. Our identification strategy exploits the locality-level variation in the intensity of the Israeli-Palestinian conflict in the West Bank during the Second Intifada (2000-2005). We show that an increase in family experience of conflict has large negative long-term effects on the educational attainment of children as measured by grade point averages. We find that non-cognitive rather than cognitive skills are the channels through which exposure affects children's educational achievement.
\end{abstract}

Keywords Conflict $\cdot$ Schooling $\cdot$ Children $\cdot$ Non-cognitive skills

JEL Classification D10 · I20 · F51 · O12

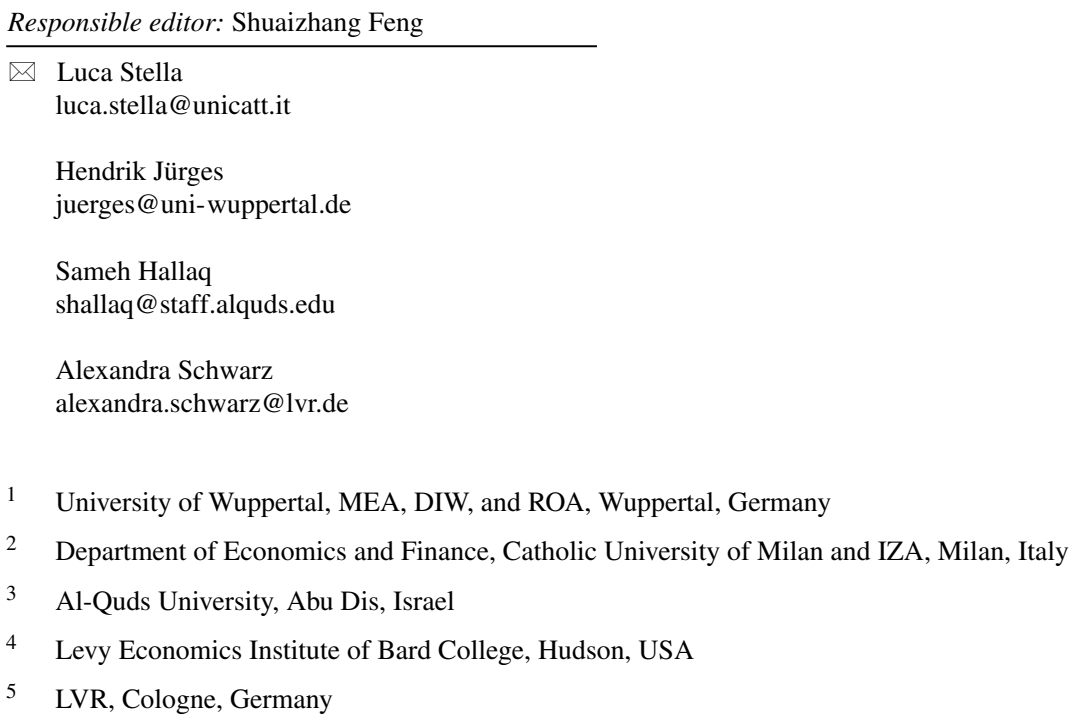




\section{Introduction}

Violent conflicts can have enormous social and economic consequences for the affected civilian population. These consequences can be especially dramatic for children. A growing body of research from different countries provides robust evidence of the short-run adverse effects of conflicts on a large array of children's outcomes, including, for instance, health (Minoiu and Shemyakina 2014; Akresh et al. 2012), psychological well-being (Blattman and Annan 2010), child labor (Di Maio and Nandi 2013), and education (Shemyakina 2011; Brück et al. 2019; Di Maio and Nisticò 2019; Di Maio and Nandi 2013). In addition, exposure to conflict may also affect outcomes of individuals later in life, particularly if happens during early childhood, which may be a sensitive or even critical period for the development of important skills in life (Conti and Heckman 2012). The empirical literature on the long-run effects of conflict on education has been growing steadily in recent years (Akresh and De Walque 2008; León 2012; Arcand and Wouabe 2009; Bertoni et al. 2019; Pivovarova and Swee 2015; Akbulut-Yuksel 2014; Justino et al. 2013; Verwimp and Van Bavel 2013; Chamarbagwala and Morán 2011).

Our paper contributes to the literature on long-run effects of early-childhood exposure to violence by exploring the role of cognitive and non-cognitive skill development as a mechanism through which conflict exposure may affect educational attainment (and hence future health or labor market outcomes). The data we have collected allow us to explore potential causal channels through which exposure to conflict - which is measured at the household level—may influence educational outcomes. The results of such analyses are critical for designing and implementing effective policies that protect children from negative conflict consequences (Justino et al. 2013). We are not aware of any papers in the related literature that have looked at skill development as a potential mechanism in such detail. We fill this gap by explicitly analyzing cognitive skills (measured by a 184 item IQ test) and non-cognitive skills (personality and behavioral problems measured by the Big 5 inventory and the Strengths and Difficulties Questionnaire) as possible causal mechanisms. Hence, this paper contributes to our knowledge on how the early-childhood environment affects long-term outcomes (see, for instance, Currie (2001), Heckman (2000), Krueger and Whitmore (2001), Gould et al. (2011), and Kaestner and Callison (2011)). The results of the present analysis are in line with those by Heckman et al. (2013) on the positive long-term effects of "beneficial" interventions (i.e., preschool programs) via noncognitive (but not via cognitive) skills. In fact, we find negative long-term effects via non-cognitive (but not via cognitive) skills of a "harmful" intervention such as a violent conflict.

Specifically, our study is set in the context of the Israeli-Palestinian conflict. We study intelligence, non-cognitive skills and school grades in West Bank students seven years after the end of the Second Intifada, and we compare children whose families were directly affected by this conflict with those who were not. The Second Intifada took place between September 2000 and February 2005. During that period, a resurgence in the intensity of violence between Palestinian organizations and Israeli Defense Forces (IDF) resulted in more than 38,000 casualties (dead and wounded). It claimed the life of about 4000 Palestinian and 1000 Israeli civilians 
( $18 \%$ of which were children), with the number of fatalities varying markedly across localities and over time. ${ }^{1}$ For example, 2002 saw a peak in the number of deaths in the context of a large-scale Israeli military offensive, Operation Defensive Shield, in response to Palestinian suicide attacks. This military operation was concentrated primarily among some very violent localities in the West Bank, such as Jenin, Nablus, and Hebron (Mansour and Rees 2012). During the conflict, the IDF engaged in operations involving violence also against civilians in Palestine, such as occupations of Palestinian houses, beatings and abuse. Tight restrictions were imposed on the movement of people and goods within the Palestinian territories and between the territories and Israel (see, for instance, B'Tselem (2002) and Calì and Miaari (2013)). These mobility restrictions further depressed the Palestinian economy, leading to a rise in unemployment, a decline in real wages, and a reduction in the quantity and quality of food (Miaari and Sauer 2011). The initial building of the separation barrier across the West Bank contributed to a further division of Palestinian communities by isolating them from their surroundings (UNSCO 2014). The social and political consequences of this conflict did not stop with the end of the Second Intifada but continue to this day (Jaeger et al. 2012). An important aspect of the Second Intifada relevant to researchers is the temporal and spatial variation in the level of violence-which can be fruitfully exploited for the identification of causal effects. This is also made possible by the detail of information on the intensity of the conflict as it is made publicly available by non-governmental organizations such as B'Tselem. ${ }^{2}$

Another feature of our analysis is the use of a direct, self-reported measure of household exposure to a violent event during the conflict. Such direct measures of exposure are often missing from conflict data. While retrospective self-reports have limitations, such as recall bias, they improve our understanding of the consequences of conflict (Brück et al. 2019). Moreover, an individual family's exposure to the conflict might depend on a range of characteristics that are also linked with children's educational attainment, and is thus likely not exogenous. Therefore, we exploit the locality-level variation in conflict intensity to identify exogenous variation in households' experience of conflict-related events. A recent example of an analysis that employs the number of fatalities in a given locality to measure conflict intensity during the Second Intifada is Brück et al. (2019). The authors use the year-to-year variation in the number of (Palestinian) victims at the school locality to investigate the short-term effects of violence on students' probability to pass the high school final exam. We also use the locality-level number of fatalities as a measure of conflict intensity, but since we look at long-run effects of the conflict, we employ the

\footnotetext{
${ }^{1}$ For a detailed description of the different periods of violence during the Second Intifada, see, for instance, Jaeger and Paserman (2008).

${ }^{2} \mathrm{~B}$ 'Tselem is an Israeli human rights organization, which provides information on each Palestinian and Israeli fatality, including the date, location and circumstances of the fatality, and the age, sex and locality of residence of the victim since the beginning of the Second Intifada. The B'Tselem data has been employed by many authors analyzing the Israeli-Palestinian conflict (see, for example, Jaeger et al. (2012) or Mansour and Rees (2012)). They are considered as being accurate and reliable by both Israelis and Palestinians.
} 
cumulative number of victims over the entire Second Intifada period. ${ }^{3}$ Our identification relies on the assumption that the number of fatalities in the household locality only influences children's grades several years later through family exposure to conflict. This assumption may not hold if there exist time-invariant unobservable factors at the locality level correlated with both conflict intensity and children's school performance. To circumvent this problem, we control for a large array of local labor market and institutional characteristics, such as unemployment rate, the proportion of Palestinian workers employed in Israel, the daily wage per locality, the fraction of low-skilled workers, poverty rate, the proportion of the locality under the Israeli administration as well as the presence of the separation wall. In addition, to further support the validity of our findings, in the sensitivity analysis we add province fixed effects to our model. We show that our main effect is substantially robust to the inclusion of time-invariant differences across provinces, and is thus not affected by potential bias resulting from pre-existing regional differences in social and economic development, thereby boosting the confidence in our identification strategy.

Another concern regarding our identification strategy is the possibility that the number of fatalities affects child's education through mediating channels other than household exposure to conflict, such as, for instance, changes in the quality of school infrastructures. However, we can test for and subsequently exclude all channels related to conflict-induced changes in the supply of education, such as a worsening in the quality of school infrastructures. We view these results as strong evidence in support of the exclusion restriction of our identification strategy.

A further threat to the validity of our exclusion restriction arises from the endogenous sorting of households across localities in response to increased levels of violence. In particular, if households systematically move away, and children's primary education outcomes are correlated with the household decision to move, this can lead to biased estimates of family exposure to conflict. While we cannot address this concern directly, we note that in the West Bank during the Second Intifada, internal and external mobility has been extremely difficult and is still at a very low level. For example, Mansour and Rees (2012) point out that most Palestinian families living in the West Bank could not migrate because of the mobility restrictions imposed by Israel. Furthermore, data from the most recent (2007) census suggest that less than 5\% of the current West Bank residents have moved away from the their mother's place of residence at birth (PCBS 2010). ${ }^{4,5}$

For our empirical analysis, we draw on data collected in 2013 in the West Bank, which contain information on a random sample of primary school students in grades 5 to 9 and their families. These data are well suited for our purposes. First, they contain

\footnotetext{
${ }^{3}$ Thus, in contrast to Brück et al. (2019), our research question does not allow us to exploit the intertemporal variation in our conflict data and apply a difference-in-differences strategy or estimate a model that includes school fixed effects.

${ }^{4}$ The only exceptions are the districts of Tubas and Jericho, with the proportions being approximately $10 \%$ and 30\%, respectively (PCBS 2010).

${ }^{5}$ Similarly, the vast majority of children attend the closest school to their residence. In fact, according to the regulations by the Palestinian Ministry of Education and Higher Education (MoEHE), the educational governorate has to approve the transfer certificate between schools.
} 
administrative information on children's primary school grades for three subsequent school years, i.e., 2010/2011, 2011/2012 and 2012/2013. Second, they contain retrospective self-reported information on parents' experience of violence during the Second Intifada. Finally, the data contain detailed information on children's skills, thereby enabling us to shed light on the potential mechanisms through which family's exposure to conflict may affect children's school achievement. Throughout the analysis, we combine the individual level data with locality-level information on the number of fatalities from the beginning of the Second Intifada in September 2000 to February 2005, allowing us to exploit the previously discussed geographical variation in fatalities.

Overall, our results demonstrate that family exposure to conflict during the Second Intifada has long-term effects on their children's primary education achievement in the West Bank. An additional event of household exposure to conflict reduces their children's grade point averages (GPA) by 6.46 points (on a 0 to 100 scale), which corresponds to a decline of approximately 0.35 standard deviations. As regards the potential mechanisms through which the parents' exposure to conflict may affect children's performance in primary school, we show that more exposure to conflict leads to lower non-cognitive skills, such as conduct problems or a reduced level of conscientiousness. In contrast, there is little evidence that cognitive skills, although being important determinants of school achievement, are affected by family exposure to conflict. In particular, the finding that household exposure to conflict reduces children's educational achievement, because it worsens non-cognitive rather than cognitive skills, is new to the literature and crucially differentiates our work from previous studies in this area (Brück et al. 2019; Di Maio and Nisticò 2019). We note, however, that there is a psychological literature that has explored how exposure to community violence in US inner cities is linked with poor academic performance. This literature has shown associations between exposure to violence in early childhood, post-traumatic symptoms, and impaired development of emotional regulation (Osofsky 1995). Studies have identified hyperactivity and disruptive behavior as well as depressive symptoms as likely mediating channels (Schwartz and Gorman 2003; Borofsky et al. 2013). In line with our own findings, externalizing problems seem to play a bigger role than internalizing problems in mediating the effect of exposure to violence on academic achievement.

The remainder of this paper is organized as follows. Section 2 presents a description of the data. Section 3 describes the empirical specification and identification strategy. In Section 4, we report the main results of the paper and also include a set of robustness checks and heterogeneity analyses. Section 5 provides evidence on cognitive and non-cognitive skills as potential causal channels. Section 6 summarizes our findings and concludes.

\section{Data}

The data used in this paper are drawn from a new dataset collected in 2013 in the West Bank and East Jerusalem in the context of a joint research project between 
Wuppertal University, Hebrew University and Al-Quds University funded by the German Research Foundation (DFG). The dataset contains information on a sample of approximately 6000 primary school students (around 4000 girls and 2000 boysgirls were oversampled) in grades 5 to 9 and their families. ${ }^{6}$ Students were randomly selected, stratified by grade level, from a random sample of 100 single-sex primary schools across the West Bank, stratified by region (North, Center and South) and school authority (public or UNRWA schools). ${ }^{7,8}$

The dataset combines administrative and survey data. First, it contains individual grades in each subject for three subsequent school years, i.e., 2010/11, 2011/12, and 2012/13. ${ }^{9}$ This information was obtained from the Ministry of Education's administrative records. We use this information to create our main educational outcome in primary school: student GPA, which is computed as the average of the most recent grades (i.e., school year 2012/2013) obtained in the six main subjects: Arabic, English, Science, Mathematics, Social Science and National Education, and Religious Education. This set of subjects covers more than $80 \%$ of the weekly lessons (UNESCO 2011). Students are graded on a scale ranging from 0 to 100. It is worth noting that independent of type, all schools in the West Bank follow the same national curriculum, provided by the Ministry of Education, and apply the same evaluation criteria (UNESCO 2011)..$^{10}$

Second, our dataset provides information at the individual and household level collected through paper-and-pencil student and family questionnaires. Of particular importance for our study is the parent-reported information on whether households themselves were exposed to violent events during the Second Intifada. This information is used to create the main explanatory variable in our analysis. The following question was asked of each household respondent: "During the Second Intifada, has your household experienced any of the following events?". The list of possible answers comprises seven items and reflects two aspects of the exposure to conflict: violence and economic consequences. For the purpose of this paper, we focus on the

\footnotetext{
${ }^{6} \mathrm{We}$ provide a detailed description of the sampling requirements and many ancillary results in our Appendices A, B and C at: https://tinyurl.com/yb3v6tvh

${ }^{7}$ UNRWA schools are run by the United Nations Relief and Works Agency for Palestine Refugees in the Near East (UNRWA). They provide basic education to children of Palestinian refugees until grade 9. All types of school are required to follow the same national curriculum. Furthermore, primary schools are predominantly single-sex, representing $76 \%$ of the public schools and $85 \%$ of the UNRWA schools in the West Bank during the academic year 2011/2012 (MoEHE 2012).

${ }^{8}$ Schools, and in particular refugee camps, received financial aids from UNRWA, which also implemented the reconstruction process of the camps after the conclusion of the Second Intifada (UNRWA 2007). The support for the most needed families (families of fatalities, prisoners or those families that the Israeli army demolished their homes) comes through the informal channels to meet the basic need of those households. Since changes in the quality of school infrastructures could violate the exclusion restriction of our identification strategy, in Table 9 we show that there is no response of the quality of school infrastructures to conflict intensity.

${ }^{9}$ After the Second Intifada, the overall trend in drop-out rates from primary education in the West Bank is less than 1\% (PCBS 2013).

${ }^{10}$ Similar to any school system that does not rely exclusively on standardized tests, local standards may be different, but we have no indication or evidence that students are systematically graded differently according to different standards in different schools.
} 
following violent events: "House was searched"; "House was occupied while you were in it"; "House was occupied and you were forced out"; "House was sealed or destroyed." Whereas one-quarter of households reported that the house was searched, between 5 and $8 \%$ reported any of the other events. Furthermore, households are also asked about the year and month of the event. Among the households who reported exposure to conflict, $40 \%$ did not provide an answer regarding the date. A small number of households reported events that happened during the First Intifada, some more reported events that happened after the end of the Second Intifada. These events were excluded from the analysis. Inspection of the reported dates further indicates that the events often took place in the same month and year, suggesting that answers to our exposure questions refer to the same episode. Apparently, there is no single "correct" way to use the self-reported information on exposure to conflict in our setting. For ease of interpretation, we use the raw count of events reported during the Second Intifada (a score ranging from zero to four). In a robustness analysis, we consider alternative definitions of exposure to conflict, and demonstrate that our results are not sensitive to these changes.

Third, our data contain information on children's cognitive and non-cognitive skills, which we use to study the mechanisms by which household exposure to conflict affects educational attainment. Cognitive ability is measured by three major cognitive tests (verbal, numerical, and figural), each consisting of subtests covering a wide range of item content (e.g., analogies, series, sentence completion, vocabulary). The subtests were selected and adapted from established tests of general ability: the Cognitive Ability Test (Thorndike and Hagen 1971), Milta-a Hebrew version of the Lorge Thorndike Test (Ortar and Shachor 1980), Standard Progressive Matrices (Raven 1983), and the Culture Fair Intelligence Test (Cattell and Cattell 1965).

Our indicators of non-cognitive skills are often used measures of mental health and personality traits. We assess student mental health using the Strengths and Difficulties Questionnaire (SDQ), a 25-item behavioral screening questionnaire designed to measure mental health problems in children and adolescents between 3 and 16 years old (Goodman 1997; Goodman et al. 2000). ${ }^{11}$ SDQ items are used to construct three indicators of children's mental health: the total difficulties scale, and the corresponding subscales for "internalizing" symptoms (emotional symptoms and peer problems) and "externalizing" behavior problems (conduct problems and hyperactivity/inattention). "Internalizing" symptoms are linked to anxiety and depression, whereas "externalizing" behavior problems are related to deviant and aggressive behaviors. Items for these two subscales are listed in Table 11 in our Appendix A. To facilitate interpretation, we standardize scores for internalizing and externalizing problems to have mean zero and standard deviation one.

Student personality is measured in terms of the Big Five model, a widely accepted approach for conceptualizing personality (Barenbaum and Winter 2008; Goldberg 1993), which is increasingly used also in labor market research to assess "soft"

\footnotetext{
${ }^{11}$ The SDQ exists in three versions, to be answered by children, teachers, and parents, respectively, and is validated in many languages, including Arabic (see www.sdqinfo.org). In this paper, we use the parent-reported version included in the parental background questionnaire.
} 
skills (Heckman and Kautz 2012). According to this model, personality traits can be organized in five basic dimensions: openness, conscientiousness, extraversion, agreeableness, and neuroticism. We use a parent-reported 15-item version of the Big Five questionnaire (see Table 12 in our Appendix A). Scores on each dimension were z-standardized. ${ }^{12}$

With regard to the local context, we use locality-level information on labor market and institutional characteristics, such as type of locality (rural, urban or refugee camp), unemployment and poverty rates, the proportion of Palestinian workers employed in Israel, the daily wage per locality, the fraction of low-skilled workers (i.e., share of workers with less than 13 years of schooling), whether the locality is affected by the separation wall, and the proportion of a locality under area C. ${ }^{13}$ Localities are the smallest administrative units defined by the Palestinian Central Bureau of Statistics (PCBS) based on their economic inter-linkages. There are 528 localities overall in the West Bank. Data on such a low geographic level are available only occasionally.

Information on unemployment rate, the proportion of Palestinian workers employed in Israel, the daily wage per locality, and the fraction of low-skilled workers comes from the Palestinian Labor Force Survey collected by the PCBS. Poverty rates (available for 2009 only), the proportion of the locality under area C, and information on whether a locality is affected by the separation wall are obtained from the World Bank (Vishwanath et al. 2014). These contextual variables are then merged with the individual-level data using information on the residence of the household living in a locality.

Our most important contextual variable is the number of Palestinian fatalities at each child's school locality from September 2000 to February 2005, and is drawn from B'Tselem. These data measure local area conflict intensity during the Second Intifada. While the measures of conflict intensity used in the literature differ considerably, ${ }^{14}$ the number of conflict-related Palestinian victims can be regarded as the best proxy for Palestinian exposure to conflict in the West Bank during the Second Intifada (Amodio and Di Maio 2017).

Our analytical sample is constructed as follows: only observations with missing data for students' achievement in primary school and households' experience of political violence are excluded from the analysis. To minimize the loss of

\footnotetext{
${ }^{12}$ This information is obtained from the six instruments of our dataset. Importantly, response rates are very high, being around $84 \%$ in the parental questionnaire, and above $90 \%$ in the other instruments.

${ }^{13}$ Since 1995, the West Bank is divided into three areas: A, B and C. Figure 1 shows a map of the West Bank and the geographical division of Palestinian territories into those areas. The Palestinian National Authority (PNA) has control over both administration (e.g., health, education, sanitation, water, and taxation) and security in area A, whereas control by the PNA is limited to administration in area B, and is absent in area C (Vishwanath et al. 2014). Communities in area $\mathrm{C}$ are at higher risk of adverse life circumstances due to the lack of primary services (UNSCO 2014).

${ }^{14}$ For example, Di Maio and Nandi (2013) use the number of closure days, Calì and Miaari (2018) employ the number of IDF check points in the West Bank, and Eckstein and Tsiddon (2004) utilize the number of Israeli victims of Palestinian attacks in Israel.
} 


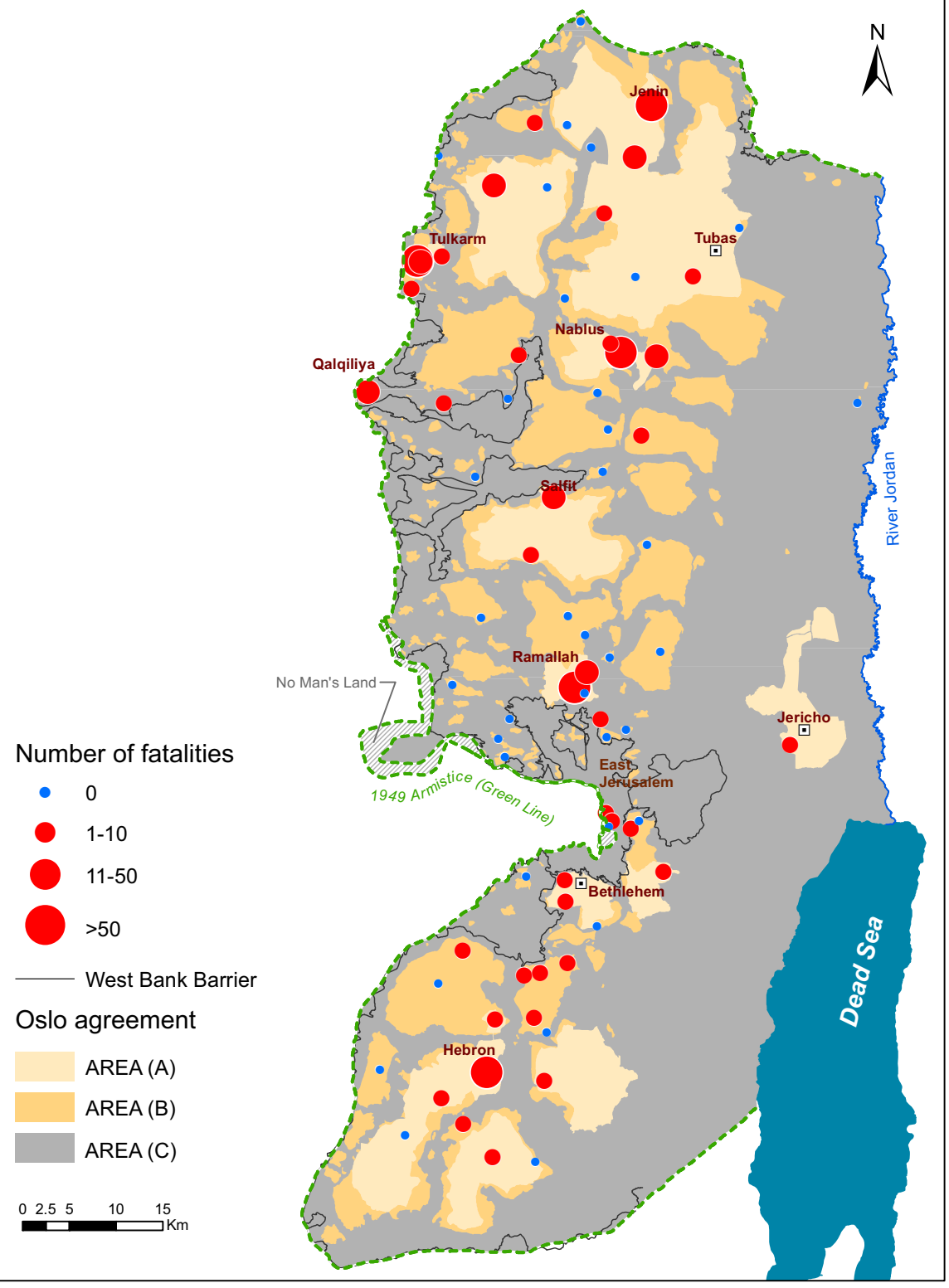

Fig. 1 Map of the West Bank, school locations and the number of Palestinian fatalities during the Second Intifada 
observations, missing values in any other variable are substituted by mean values. Additionally, an indicator for such missing values is created. ${ }^{15}$ After these restrictions, we obtain a working sample that contains 4235 children in grades 5 to 9 enrolled in 98 primary schools located across 74 distinct localities throughout the West Bank.

Table 1 reports descriptive statistics on the main variables used in the analysis. It consists of three panels, panel A for the sample at the individual level, and panel B and $\mathrm{C}$ for the corresponding samples at the school level and locality level, respectively. The children in our sample are on average 12.8 years old, and $70 \%$ are girls. Their GPA is on average 67.8 points and has a standard deviation of 17.6 points. On average, parents report to have been exposed to 0.41 conflict-related incidents during the Second Intifada. ${ }^{17} 41 \%$ of children in our sample have refugee status, meaning they are descendants of families who have been displaced after the 1948 Palestine war. $25 \%$ of fathers and $19 \%$ of mothers have a college degree, and $37 \%$ of fathers and $39 \%$ of mothers have a high school diploma. As regards children's mental health and personality, we show summary statistics before standardization. Children score, on average, 12.6 in terms of total difficulties, 6.1 in terms of "internalizing" symptoms, and 6.5 in terms of "externalizing" problems. These averages are fairly high compared with the corresponding figures from Western countries. For example, in the US children of the same age score on average 7.1 in terms of total difficulties, 4.0 in terms of "externalizing" problems and 3.0 in terms of "internalizing" symptoms (see www.sdqinfo.org). Approximately, $13 \%$ of the Palestinian workers are employed in Israel. $^{18}$

\section{Empirical methodology}

\subsection{Model specification}

The first part of our analysis is to estimate the effects of parents' exposure to conflict on their children's educational attainment. To this end, we estimate the following linear model for student school achievement:

$$
Y_{i s l}=\alpha+\beta \text { Exposure }_{i s l}+\gamma X_{i s l}+\xi U_{s l}+\lambda Z_{l}+\varepsilon_{i s l}
$$

where the index $i s l$ denotes a child $i$ enrolled in primary school $s$ and residing in locality $l$ at the year of interview. The outcome variable $Y_{i s l}$ represents GPA of child $i$ for the school year 2012/2013.

Our variable of interest is Exposure Esl $_{\text {, }}$, defined as the number of violent events during the Second Intifada reported by the household respondent (child's mother or

\footnotetext{
${ }^{15}$ While the inclusion of these observations does not substantially affect the point estimates, it does improve the precision of our estimates.

${ }^{16}$ Data from two schools which did not collect household questionnaires (containing information on households' exposure to conflict) had to be dropped from our sample.

${ }^{17}$ Approximately $40 \%$ of the households have reported at least one violent event, and among those who have reported at least one event, $95 \%$ have reported that their house was searched. This is by far the most common violent event experienced by the students' households during the Second Intifada.

18 As noted by Fallah and Saad (1227), the closure of Israeli labor market that occurred at the outset of the Second Intifada represented a major negative demand shock for the Palestinian workers employed in Israel, which in turn reduced the opportunity cost of attending school.
} 
Table 1 Descriptive statistics

\begin{tabular}{|c|c|c|c|c|}
\hline Variable & Mean & Std. Dev. & Min. & Max. \\
\hline \multicolumn{5}{|c|}{ Panel A: Individual-level. Observations: 4235} \\
\hline School achievement (2012/2013) & 67.8 & 17.6 & 7.2 & 99.5 \\
\hline Family exposure to conflict & 0.41 & 0.82 & 0 & 4 \\
\hline Child's age in years & 12.8 & 1.5 & 10 & 18 \\
\hline Girl & 0.70 & 0.46 & 0 & 1 \\
\hline Refugee status & 0.41 & 0.49 & 0 & 1 \\
\hline Mother's age & 39.5 & 6.0 & 24 & 65 \\
\hline Father's age & 44.7 & 6.5 & 27 & 91 \\
\hline High school diploma (mother) & 0.39 & 0.49 & 0 & 1 \\
\hline College degree (mother) & 0.19 & 0.40 & 0 & 1 \\
\hline High school diploma (father) & 0.37 & 0.48 & 0 & 1 \\
\hline College degree (father) & 0.25 & 0.43 & 0 & 1 \\
\hline Father is working & 0.67 & 0.47 & 0 & 1 \\
\hline Cognitive test score & 0.62 & 0.17 & 0 & 0.94 \\
\hline Numerical test score & 0.62 & 0.21 & 0 & 1 \\
\hline Figural test score & 0.58 & 0.19 & 0 & 0.97 \\
\hline Verbal test score & 0.64 & 0.16 & 0 & 0.95 \\
\hline SDQ total score & 12.6 & 5.7 & 0 & 34 \\
\hline Internalizing problems & 6.1 & 3.1 & 0 & 17 \\
\hline Externalizing problems & 6.5 & 3.6 & 0 & 19 \\
\hline Conscientiousness & 3.9 & 0.9 & 1 & 5 \\
\hline Extraversion & 3.3 & 0.7 & 1 & 5 \\
\hline Openness & 4.0 & 0.8 & 1 & 5 \\
\hline Neuroticism & 3.2 & 0.9 & 1 & 5 \\
\hline Agreeableness & 3.8 & 0.8 & 1 & 5 \\
\hline \multicolumn{5}{|l|}{ Panel B: School-level. Observations: 98} \\
\hline UNRWA school & 0.41 & 0.49 & 0 & 1 \\
\hline \multicolumn{5}{|l|}{ Panel C: Locality-level. Observations: 74} \\
\hline Fatalities & 12 & 34.5 & 0 & 229 \\
\hline Separation wall & 0.43 & 0.5 & 0 & 1 \\
\hline Locality under area $\mathrm{C}$ & 0.32 & 0.33 & 0 & 1 \\
\hline Poverty rate 2007 & 0.22 & 0.12 & 0 & 0.5 \\
\hline Rural & 0.42 & 0.5 & 0 & 1 \\
\hline Refugee camp & 0.18 & 0.38 & 0 & 1 \\
\hline Unemployment & 0.23 & 0.09 & 0 & 0.50 \\
\hline Average daily wage & 99.8 & 24.4 & 58 & 160 \\
\hline Low-skilled workers & 0.80 & 0.09 & 0.55 & 0.96 \\
\hline Palestinian workers employed in Israel & 0.13 & 0.13 & 0 & 0.54 \\
\hline
\end{tabular}

All the samples contain children for whom information on school achievement and their exposure to conflict during the Second Intifada is not missing. To minimize the loss of observations, missing entries in any other covariate are replaced using mean values. Accordingly, an indicator for such missing values is created. The cognition, mental health and personality variables are not standardized 
father) and detailed in the previous section. Thus, $\beta$ captures the impact on student GPA at the interview year of an additional event of parents' exposure to political violence at least seven years earlier. $X_{i s l}$ is a vector of individual covariates, including gender of the child, gender of the household respondent, refugee status, dummies for children's and parental age, indicators for the father's and mother's educational level, a set of dummies for the employment status of the father (i.e., employed/selfemployed, unemployed and looking for a job, unemployed and not looking for a job, unable to work/disabled, homemaker, and retired) as well as indicators for missing values of these covariates. $U_{s l}$ is a school type indicator (UNRWA vs. public school). $Z_{l}$ is the set of locality-level labor market and institutional characteristics, such as unemployment rate, the proportion of Palestinian workers employed in Israel, the log daily wage per locality, the fraction of low-skilled workers (i.e., share of workers with less than 13 years of schooling), poverty rate, the proportion of locality under area $\mathrm{C}$, the presence of the separation wall, and type of locality (rural, urban or refugee camp). Finally, $\varepsilon_{i s l}$ represents an idiosyncratic error term.

\subsection{Identification}

The need for an identification strategy arises from the potential correlation of household experience of violence during the Second Intifada with various unobservable determinants of student achievement. Such correlation, in particular related to family background characteristics but also education infrastructure, may confound our relationship of interest. One obvious concern might be, for example, that richer and better educated families - who have children of better academic ability — may reside in certain areas less prone to Palestinian violence that may have provoked counter-violence by the IDF. While we are able to control for observed background characteristics to address this concern, there may still be unobserved confounders.

We therefore apply an IV strategy to identify the long-term effect of household exposure to conflict on children's primary school achievement, with the number of Palestinian fatalities at the locality level being used as instrument for family exposure to conflict. Similar to Di Maio and Nisticò (2019), the validity of our identification strategy relies upon the assumption that the number of fatalities in the household locality has no direct effect on children's education (i.e., the exclusion restriction). However, since the present analysis focuses on the long-term academic outcomes of children, seven years after the conclusion of the conflict, we can exploit only the cross-locality variation in the total number of Palestinian victims (and not the variation over time within the locality during the Second Intifada) to identify the effect of family exposure to conflict. Thus, one potential threat to the validity of our instrument is the omitted variable bias resulting from the presence of time-invariant unobservable factors at the locality level correlated with both conflict intensity and child primary education performance. At this stage, it is worth remarking that we do not have enough power to leverage the within-locality or within-school variation since our dataset is cross-sectional in nature and contains 98 primary schools located across 74 distinct localities throughout the West Bank. Nonetheless, we deal with this issue in two ways. First, we condition our analyses on a rich set of locality-level contextual variables, detailed in the previous section. Such locality-level contextual variables are likely to mitigate the concerns of confounding factors across localities. Second, in the 
sensitivity analysis we add province fixed effects to our model (see column 8 of Table 3 ). Reassuringly, our main effect is similar to the one obtained with our main specification. Importantly, this suggests that our main result is substantially robust to the inclusion of time-invariant differences across provinces, and is thus not affected by potential bias resulting from pre-existing regional differences in social and economic development, thereby boosting the confidence in our identification strategy.

Furthermore, while it is reasonable to think that the number of fatalities may affect children's education through household exposure to conflict, there might be other mediating channels through which this may happen (e.g., changes in the quality of school infrastructures), therefore violating the exclusion restriction. To verify whether this is the case, we exploit the richness of our dataset, which also contains a school principal questionnaire as measured during the academic year 2012/2013, with unique school-level information on the quality of school infrastructures. Specifically, in Table 9 we estimate an OLS regression of the number of fatalities during the Second Intifada on potential mediating channels related to the quality of school infrastructures. To be more precise, school principals were asked to report whether their school suffered from a shortage or inadequacy — on a scale ranging from 1 (Not at all) to 4 (A lot) - in a number of school quality characteristics. These are the following: instructional materials (e.g., textbooks); supplies (e.g., papers, pencils); school buildings and grounds; heating/cooling and lighting systems; instructional space; and technologically competent staff. If we found a significant relationship, this could potentially invalidate the exclusion restriction of our identification strategy. The results reported in columns 1 to 6 of Table 9 show that the number of fatalities during the Second Intifada is not significantly correlated with potential mediating channels related to school quality characteristics (except for a marginally significant effect on technologically competent staff). We then use principal component analysis in order to combine the scores from these six questions into a more general index of school quality (see column 7). Even in this case, we confirm that the impact of the number of fatalities on this principal component indicator summarizing the school quality outcomes is small and not statistically significant. Overall, the evidence presented in Table 9 suggests that we can exclude all channels related to conflict-induced changes in the supply of education, such as a worsening in the quality of school infrastructures. To provide further evidence that the estimated effect is not confounded by such unobserved factors, we estimate our main specification by OLS including school fixed effects (see column 2 of Table 8). Reassuringly, even when controlling for school dummies, the OLS coefficient of interest remains very similar to the benchmark specification (see column 1 of Table 8). We view these tests as strong evidence in support of the exclusion restriction of our identification strategy.

Model (1) is estimated using two stage least squares (2SLS), with the following first stage regression:

$$
\text { Exposure }_{i s l}=\eta+\delta \text { Fatalities }_{l}+\theta X_{i s l}+\zeta U_{s l}+\sigma Z_{l}+v_{i s l}
$$

where Exposure $_{i s l}$ is regressed on Fatalities ${ }_{l}$, defined as the locality-level number of all conflict-related Palestinian victims during the Second Intifada. $X_{i s l}, Z_{l}$, and $U_{s l}$ are defined in the same way as in Eq. (1). Standard errors are clustered by locality, the level of variation of our instrument. 
To illustrate the variation of our instrument, Fig. 1 shows a map of the West Bank. Each circle represents a locality contained in our sample. The size of the circle indicates the locality-level number of Palestinian fatalities during the Second Intifada. Overall, Fig. 1 shows a substantial degree of variation in the number of Palestinian fatalities, with the highest levels of conflict intensity being concentrated in some very violent localities, such as Nablus, Jenin, Tulkarm, Hebron and Ramallah. Figure 2 shows the relationship between the total number of fatalities during the Second Intifada at the governorate level (there are 11 governorates in the West Bank) and the average level of exposure to conflict as reported by parents. This graph reflects the (first stage) variation we exploit in our analysis.

\section{Results}

\subsection{Main results}

Table 2 reports the estimates of the effects of an increase in household exposure to conflict during the Second Intifada on children's primary school achievement obtained from an OLS regression (column 1) and from a 2SLS regression (column 4). In addition, we show the corresponding results from the reduced form (column 2) and first stage (column 3) regressions. As described in the previous section, in each regression we include individual-level, school-level, and locality-level control variables.

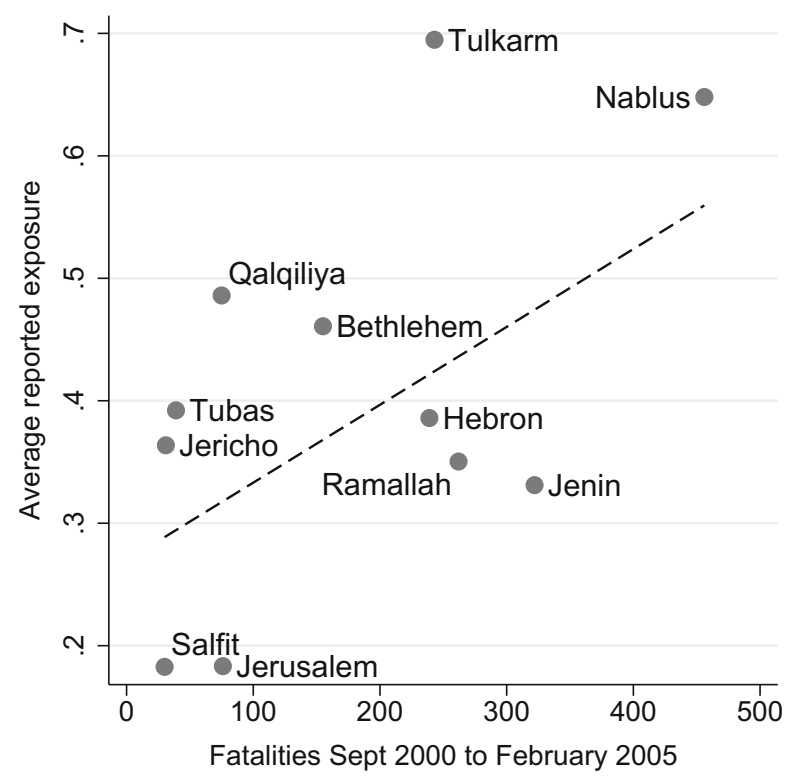

Fig. 2 Correlation between average exposure (number of reported events) and total number of Second Intifada fatalities, by governorate 
Table 2 Effects of family exposure to conflict on children's primary school GPA, main specification

\begin{tabular}{lllll}
\hline & $(1)$ & $(2)$ & $(3)$ & $(4)$ \\
& OLS & Reduced form & First stage & 2SLS \\
Dep. var.: & Child GPA & Child GPA & Family exposure to conflict & Child GPA \\
\hline Family exposure to conflict & $-1.317^{* * *}$ & & & $-6.464^{* * *}$ \\
& $(0.268)$ & & & $(1.765)$ \\
Fatalities (in hundreds) & & $-2.410^{* * *}$ & $0.373^{* * *}$ & \\
& & $(0.680)$ & $(0.050)$ & 55.5 \\
First stage $F$ statistic & & & 55.5 & 67.83 \\
Mean of dep. var. & 67.83 & 67.83 & 0.42 & 17.63 \\
SD of dep. var. & 17.63 & 17.63 & 0.82 & 4235 \\
Observations & 4235 & 4235 & 4235 & \\
\hline
\end{tabular}

Standard errors are reported in parentheses and are clustered at the locality level. All regressions include individual-, school- and locality-level controls. Specifically, individual-level controls include gender of the child, gender of the household respondent, refugee status, dummies for children's and parental age, indicators for the father's and mother's educational level, a set of dummies for paternal employment status, as well as indicators for missing values in these covariates. The school-level control variable is an indicator for UNRWA versus public school. Locality-level variables contain unemployment rate, poverty rate, the proportion of locality under area $\mathrm{C}$, the presence of the separation wall, type of locality (rural, urban or camp), average daily wage, the fraction of low-skilled workers and the fraction of Palestinian workers employed in Israel. *Significant at $10 \%$; * significant at $5 \%$; ***significant at $1 \%$

The OLS coefficient suggests a negative and significant association between households' exposure to conflict and their children's school performance: an additional event of parents' experience of conflict is associated with a 1.32 point decrease in student GPA in primary school, which corresponds to approximately $8 \%$ of a standard deviation. The reduced form regression suggests that GPA drops by approximately 2.4 points per one hundred fatalities in the locality.

The first stage regression shows that one hundred more fatalities in the locality increase parents' exposure to conflict by 0.37 events on average. With a first stage $F$ statistic of 55, our instrument easily passes conventional thresholds for strong instruments. The 2SLS coefficient on parents' exposure to conflict remains negative and statistically significant. We find that one additional event of parents' exposure to conflict induced by the Second Intifada reduces the primary school GPA of their children by 6.46 points. This effect represents a decline of about $35 \%$ of a standard deviation.

The 2SLS estimate is much larger in absolute value than the OLS estimate. Although we have no theoretical prior as to the direction in which OLS would be biased compared with the true causal effect of exposure, the size of our 2SLS coefficients may raise concerns about the validity of our results. Large 2 SLS - compared with OLS - estimates are quite common in applied research and three explanations can be put forward. The first is measurement error in the explanatory variable, which (if classical) attenuates the OLS coefficients. Clearly, if some households who have experienced violence do not report this in our survey, whereas others over-report events, and if misreporting is uncorrelated with the error term, OLS estimates would 
be biased towards zero. However, it seems at least equally plausible to assume that misreporting is in some way related to unobserved determinants of student achievement. The second explanation is that the IV approach identifies (a weighted average of) complier-specific causal effects, which can potentially be larger than OLS estimates. It is plausible that at least among always-takers (households prone to conflict events no matter what the level of conflict in the locality) the effect is smaller than among compliers (households only affected if the level of conflict in the locality is high). If this also holds for never-takers is unclear. A third explanation-potentially damaging to the IV approach - is that the exclusion restriction does not hold. Of course, this cannot be entirely ruled out in our setting. To partially address this concern, we note that the reduced form coefficients for all specifications clearly show that locality-level conflict intensity during the Second Intifada is associated with worse educational attainment more than seven years later, and that this association is robust to a number of specification changes (reduced form results are shown in Tables 14 and 15 in our Appendix B). Thus, even if the exclusion restriction did not hold, there was robust evidence that the violent political conflict has long-term consequences for educational attainment. This reduced form analysis is similar to what most of the literature has done when data on individual experience of conflict are lacking (see, for instance, Brück et al. (2019)).

To compare our results with those obtained in the literature, we note that Brück et al. (2019), analyzing the short-term effects of conflict on individual test scores for the high school final exam, find that a one standard deviation increase in the number of fatalities reduces average test scores by about $1 \%$ relative to the overall mean. Our findings are very similar: the reduced form coefficient implies that a one standard deviation increase in the number of fatalities reduces student GPA in primary school by $1.2 \%$ relative to the overall mean. ${ }^{19}$

As previously mentioned, we also estimate a range of regressions with alternative operational definitions of the exposure variable, obtaining very similar results. Importantly, our instrument does not predict exposure to conflict before or after the Second Intifada (see columns E and F of Table 13 in our Appendix B). We interpret this as evidence that the instrument does not pick up any trends in location-specific levels of violence.

\subsection{Robustness checks and heterogeneous effects}

We assess the robustness of our main results to a number of further specification changes.

First, in column (1) of Table 3 we check the sensitivity of our results to a change in the functional form of the first stage and reduced form regressions. The major concern here is that exposure to conflict and GPA may not follow linear functions of the number of fatalities. To allow for this possibility, we have recoded our instrument

\footnotetext{
${ }^{19}$ As in Brück et al. (2019), we compute this number as the percentage point reduction in GPA per standard deviation increase in the number of fatalities, $[(-2.4 / 100) \times(34.5)=-0.83]$, which, given that the mean value of the dependent variable is 67.8 , equals a $1.2 \%$ reduction.
} 


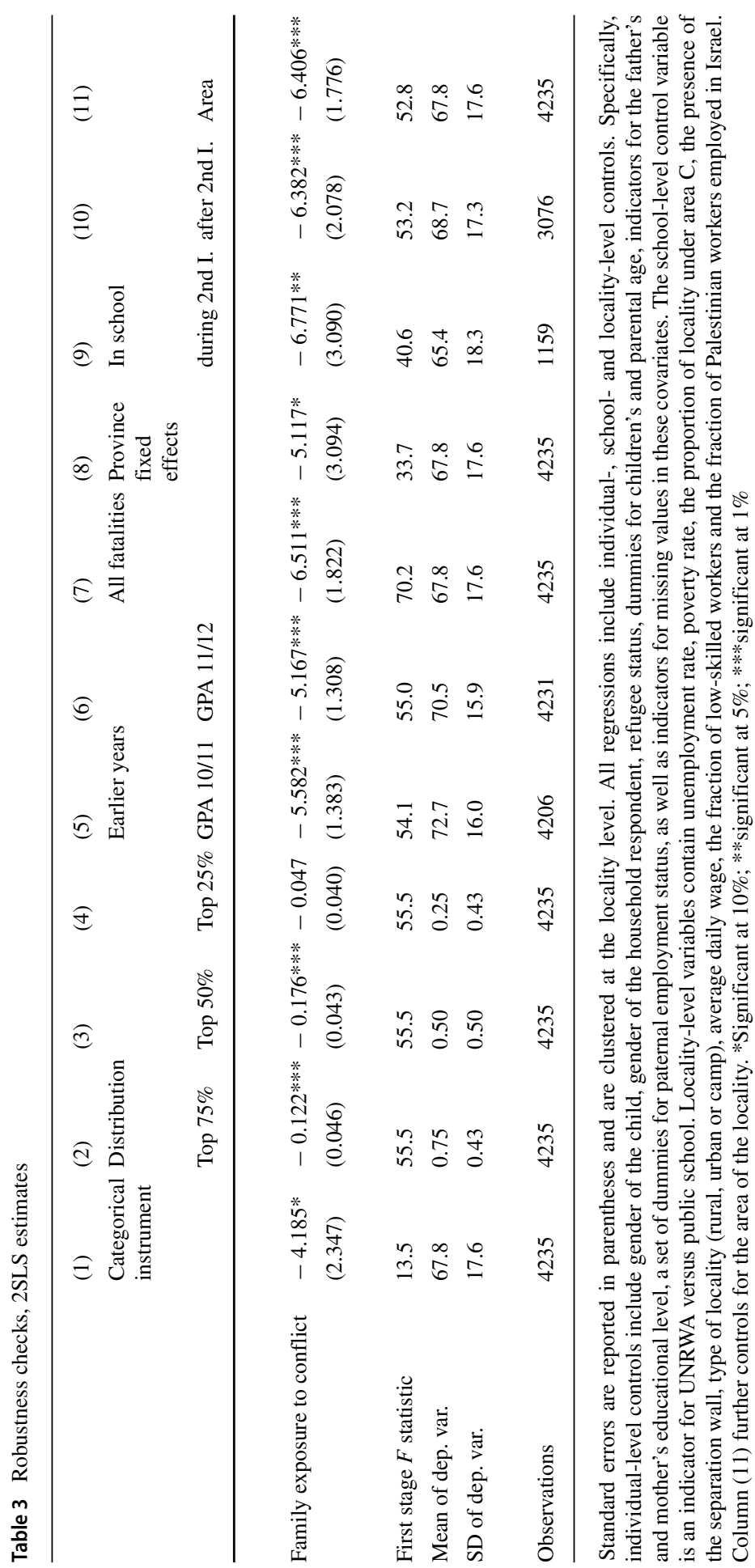


into 4 categories (as shown in Fig. 1): 0 fatalities, 1-10 fatalities, 11-50 fatalities, and $>51$ fatalities. Our point estimate changes somewhat, we lose precision and the first stage $F$ statistic decreases, but the qualitative result remains.

Second, to investigate heterogeneous effects across the distribution of GPA, in columns (2) to (4) we report the treatment effects at the 25th, 50th and 75th percentiles. Our results suggest that the effect of family exposure to conflict induced by the Second Intifada is concentrated in the lower quantiles of the GPA distribution. In other words, the long-term effects of family exposure to conflict induced by the Second Intifada seem to be driven by poor academically performing students.

Third, another concern regards the sensitivity of our findings with respect to the year in which school achievement in primary school is measured. As previously mentioned, our dataset provides information on student GPA not only for the school year 2012/2013 but also for the two preceding school years, i.e., 2010/2011 and 2011/2012. Hence, we run two additional 2SLS regressions of model (1) using student GPA for the school years 2010/2011 (column 5) and 2011/2012 (column 6) as alternative outcomes. Results remains qualitatively unchanged relative to the main specification: the coefficient on family exposure to conflict has negative and significant effects on children's GPA in primary school. Note, however, that point estimates are actually smaller in the two earlier years than in 2012/13. This suggests that effects on student GPA do not tend to subside over time. We interpret this as corroborating evidence for the plausibility and usefulness of our long-term analysis.

Fourth, in column (7) we verify the robustness of our results when using a broader measure of conflict intensity that includes the locality-level number of all Palestinian and Israeli victims during the Second Intifada. The reason for this check is that both sides of the conflict may react in a regular and predictable way to violence against them. This would imply that an increase in the number of conflict-related Israelis fatalities may lead to more violent actions against the civilian population in the West Bank. Again, the estimated parameter resembles closely the one obtained in the benchmark specification.

Next, we check what happens when we include governorate fixed effects (Column 8) in model (1). Identification then rests on within-governorate variation in the intensity of conflict. Differences in exposure to violence or children's educational attainment that are linked to the larger region are hence controlled for-addressing potential concerns about the validity of our instrument. We find that the coefficient of interest is not only quantitatively similar to the benchmark specification (see column 4 of Table 2), but also preserves the statistical significance at the $10 \%$ level, hence strengthening the confidence in our identification strategy.

In a related robustness check, we exclude single governorates one at a time to examine whether the results are driven by a specific governorate. This exercise, of which we do not report detailed results, confirms that our main results are robust to this change (Tables 4 and 5).

Furthermore, in columns (9) and (10) we split the sample in two parts based on the date of birth of the children in our sample. Specifically, in column (9) we restrict the sample to all children born before February 2000. These children have attended school for at least one year during the Second Intifada. One might argue that some part of the effect we measure is not due to parental exposure to conflict but rather 
Table 4 Effects of child cognitive and non-cognitive skills on GPA, OLS estimates

\begin{tabular}{|c|c|c|c|}
\hline \multirow{3}{*}{ Dep. var.: } & (1) & (2) & (3) \\
\hline & Child GPA & Child GPA & Child GPA \\
\hline & Separate regression & Joint regression & Joint regression \\
\hline \multirow[t]{2}{*}{ Cognitive ability } & $8.595 * * *$ & & \\
\hline & $(0.610)$ & & \\
\hline \multirow[t]{2}{*}{ Numeracy } & $6.769 * * *$ & $2.182 * * *$ & $2.072 * * *$ \\
\hline & $(0.488)$ & $(0.476)$ & $(0.449)$ \\
\hline \multirow[t]{2}{*}{ Figural } & $6.834 * * *$ & $1.320 * * *$ & $1.530 * * *$ \\
\hline & $(0.506)$ & $(0.427)$ & $(0.441)$ \\
\hline \multirow[t]{2}{*}{ Verbal } & $8.328 * * *$ & $5.153 * * *$ & $5.150 * * *$ \\
\hline & $(0.546)$ & $(0.514)$ & $(0.501)$ \\
\hline \multirow[t]{2}{*}{ SDQ total } & $-4.348 * * *$ & & \\
\hline & $(0.310)$ & & \\
\hline \multirow[t]{2}{*}{ Internalizing } & $-2.615^{* * *}$ & -0.315 & \\
\hline & $(0.318)$ & $(0.305)$ & \\
\hline \multirow[t]{2}{*}{ Externalizing } & $-4.583^{* * *}$ & $-3.196^{* * *}$ & \\
\hline & $(0.291)$ & $(0.318)$ & \\
\hline \multirow[t]{2}{*}{ Openness } & $2.782 * * *$ & & $0.712 * * *$ \\
\hline & $(0.289)$ & & $(0.237)$ \\
\hline \multirow[t]{2}{*}{ Conscientiousness } & $3.823 * * *$ & & $2.593 * * *$ \\
\hline & $(0.275)$ & & $(0.285)$ \\
\hline \multirow[t]{2}{*}{ Extraversion } & $-0.848 * * *$ & & -0.362 \\
\hline & $(0.264)$ & & $(0.232)$ \\
\hline \multirow[t]{2}{*}{ Agreeableness } & $1.404 * * *$ & & -0.280 \\
\hline & $(0.254)$ & & $(0.215)$ \\
\hline \multirow[t]{2}{*}{ Neuroticism } & $-1.195 * * *$ & & -0.243 \\
\hline & $(0.229)$ & & $(0.203)$ \\
\hline Observations (minimum) & 4089 & 4089 & 4150 \\
\hline
\end{tabular}

Standard errors are reported in parentheses and are clustered at the locality level. All regressions include individual-, school- and locality-level controls. Specifically, individual-level controls include gender of the child, gender of the household respondent, refugee status, dummies for children's and parental age, indicators for the father's and mother's educational level, a set of dummies for paternal employment status, as well as indicators for missing values in these covariates. The school-level control variable is an indicator for UNRWA versus public school. Locality-level variables contain unemployment rate, poverty rate, the proportion of locality under area $\mathrm{C}$, the presence of the separation wall, type of locality (rural, urban or camp), average daily wage, the fraction of low-skilled workers and the fraction of Palestinian workers employed in Israel. *Significant at 10\%; **significant at 5\%; ***significant at 1\%

to disruptions to teaching, such as closing of schools, detainment of teachers, road closures keeping children from reaching schools and so on Brück et al. (2019). In column (10) we focus on children born in February 1999 or later, who have entered 


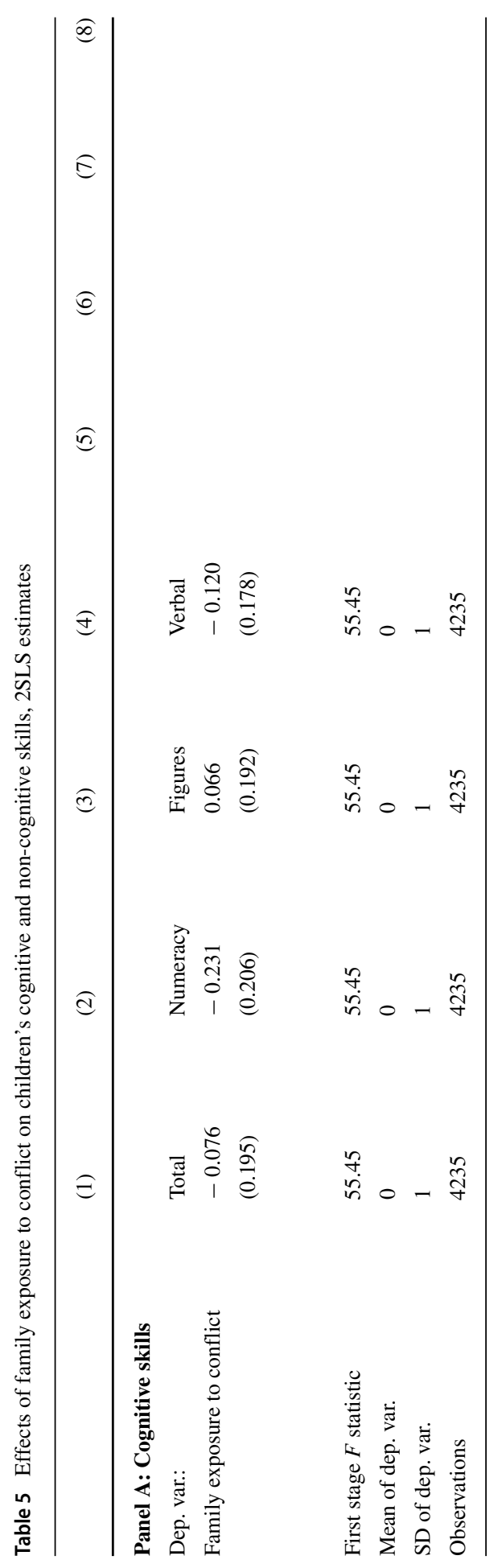




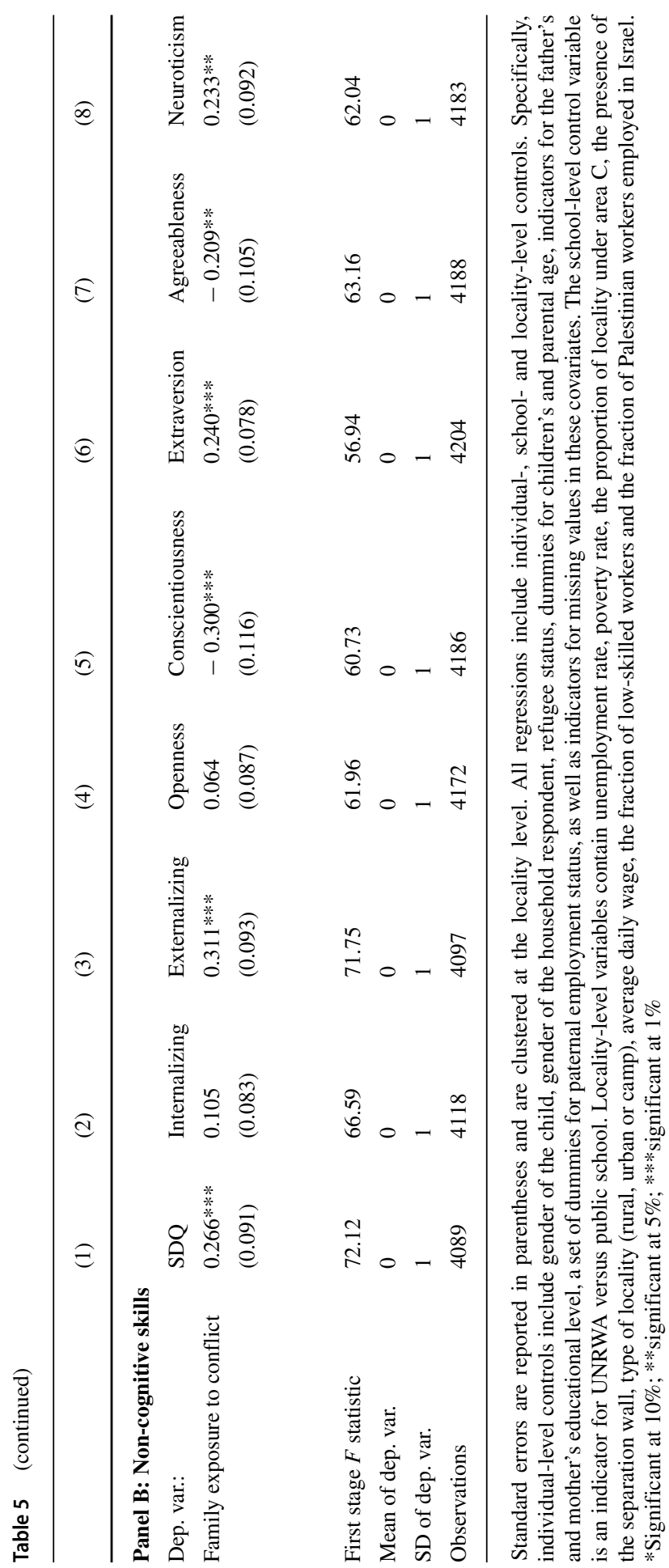


Table 6 Balancing tests. Effects of pre-Second Intifada locality-level characteristics on fatalities during the Second Intifada-locality-level specification-OLS

Dep. var.:

Unemployment Employed in Israel Avg. Wage Low-skilled workers Urban

Fatalities (in hundreds) -0.0167

(0.0157)

$-0.0942$

(0.0617)

0.215

0.179

SD of dep. var.

0.101

Observations

49
$-0.1175^{* *}-0.0664 * * *$

(0.0513) (0.0230)

4.371

0.868

$0.153 \quad 0.0707$

49

49
$0.5102 * * *$

$(0.1556)$

Robust standard errors are reported in parentheses. Locality-level specification. Unemployment, Palestinian workers employed in Israel, average daily wage and the proportion of low-skilled workers are a set of pre-Second Intifada locality-level characteristics collected in $1999 *$ Significant at 10\%; **significant at $5 \%$; ***significant at $1 \%$

school in September 2005 (after the end of the Second Intifada), and whose schooling has not been directly affected by the conflict. Taken together, the results in columns (9) and (10) do not provide any evidence for differential effects of household exposure to conflict by date of birth. In column (11) we show that our main effect is qualitatively similar when we control for the log of the area of the locality (in square kilometer). ${ }^{20}$ An additional concern regards the sensitivity of our findings with respect to the most violent localities included in the sample and whether these are driven by a specific locality. We have thus selected the ten most violent localities (in terms of the number of fatatlities) during the Second Intifada (i.e., Nablus, Jenin, Tulkarm, Hebron, Ramallah, Qualquiliya, Tulkarm Camp, Al Bireh, Askar Camp and Qabatiya). Our results still hold when we exclude from our sample one locality at a time (see Table 18 in our Appendix B).

In Table 6 we conduct a set of balancing tests, aimed at verifying that localities that have been exposed differently by fatalities during the Second Intifada are similar with respect to a number of pre-Second Intifada characteristics at the locality level. To this end, we collected information on a set of pre-Second Intifada localitylevel characteristics in $1999 .{ }^{21}$ Overall, we find that the pre-Second Intifada rate of

\footnotetext{
${ }^{20}$ As regards the geographical features of the localities, we note that our specifications already control for whether the locality is affected by the separation wall, and the proportion of a locality under area C. In particular, the former accounts for the presence of a shared border with Israel during the Second Intifada; the latter can be regarded as a proxy for the interaction with Israel, since area $\mathrm{C}$ implies that the Palestinian National Authority (PNA) has no control over these areas (neither security nor administration): most of the localities in area $\mathrm{C}$ are situated in the close vicinity of Israeli settlements.

21 The available locality-level labor market indicators provided by Palestinian Labor Force Survey are collected since 1999, such as, for example, unemployment rate, the proportion of Palestinian workers employed in Israel, the log daily wage per locality, and the fraction of low-skilled workers (i.e., share of workers with less than 13 years of schooling). Notice that in columns 1-4 the number of observations
} 
Table 7 Effects of family exposure to conflict on children's primary school GPA, adding controls for 1999 characteristics

(1)

2SLS-baseline
(2)

2SLS—adding 1999 controls
Family exposure to conflict

First stage $F$ statistic

Mean of dep. var.

SD of dep. var.

Locality-level controls in 1999

Observations
$-6.464 * * *$

55.45

67.83

17.63

No

4235
$-8.974 * * *$

32.33

67.83

17.63

Yes

4235

Standard errors are reported in parentheses and are clustered at the locality level. All regressions include individual-, school- and locality-level controls. Specifically, individual-level controls include gender of the child, gender of the household respondent, refugee status, dummies for children's and parental age, indicators for the father's and mother's educational level, a set of dummies for paternal employment status, as well as indicators for missing values in these covariates. The school-level control variable is an indicator for UNRWA versus public school. Locality-level variables contain unemployment rate, poverty rate, the proportion of locality under area $\mathrm{C}$, the presence of the separation wall, type of locality (rural, urban or camp), average daily wage, the fraction of low-skilled workers and the fraction of Palestinian workers employed in Israel. Column (2) also includes controls for locality-level contextual characteristics in 1999: unemployment, average daily wage, the fraction of low-skilled workers and the proportion of Palestinian workers employed in Israel. *Significant at $10 \%$;**significant at $5 \%$; ***significant at $1 \%$

unemployment and the pre-Second Intifada fraction of Palestinian workers employed in Israel are not significantly correlated with the number of fatalities during the Second Intifada (see columns 1 and 2). At the same time, we find a significant relationship between the number of fatalities and the average daily wage, the proportion of low-skilled workers and urban area (see columns 3, 4 and 5). While we cannot rule out the possibility that fatalities during the Second Intifada are not randomly assigned across localities, we note that similar results have also been found by previous studies, e.g., Calì and Miaari (2015) and Miaari et al. (2012). To partially address this concern, in Table 7 we control for all the pre-Second Intifada covariates included in the balancing tests. Reassuringly, our main result remains negative and highly statistically significant, although the point estimate becomes larger (see column 2). This result mitigates concerns related to omitted variables bias. We thus argue that selection issues should not be a major source of concern for our analysis (Tables 8 and 9).

A remaining issue about the identification of the long-run effect of family exposure to conflict on education concerns the fact that families have continuously been exposed to conflict even after 2005. To dispel this issue, in columns 2 and 4 of Table 10 we consider the 2 SLS and reduced form relationships once we control for fatalities after the conclusion of the Second Intifada. In both cases we show

reduces to 49 (instead of 74) since the Palestinian Labor Force Survey does not collect labor market indicators for all localities in our sample. 
Table 8 Effects of family exposure to conflict on children's primary school GPA, adding school fixed effects

(1)

OLS-baseline
(2)

OLS—adding school FE

$-1.139 * * *$
$(0.295)$
67.83
17.63
Yes
4235

4235
Family exposure to conflict

Mean of dep. var.

SD of dep. var.

School FE

Observations

-1.317 ***
$(0.268)$
67.83
17.63
No
4235

Standard errors are reported in parentheses and are clustered at the locality level. All regressions include individual-, school- and locality-level controls. Specifically, individual-level controls include gender of the child, gender of the household respondent, refugee status, dummies for children's and parental age, indicators for the father's and mother's educational level, a set of dummies for paternal employment status, as well as indicators for missing values in these covariates. The school-level control variable is an indicator for UNRWA versus public school. Locality-level variables contain unemployment rate, poverty rate, the proportion of locality under area $\mathrm{C}$, the presence of the separation wall, type of locality (rural, urban or camp), average daily wage, the fraction of low-skilled workers and the fraction of Palestinian workers employed in Israel. Column (2) also includes school fixed effects. *Significant at $10 \%$; **significant at $5 \%$; ***significant at $1 \%$

that the coefficient on fatalities during the Second Intifada changed little relative to the benchmark specification, whereas the coefficient on fatalities after the Second Intifada is much smaller in magnitude and not statistically significant. We interpret this as evidence that the number of fatalities after the end of the Second Intifada does not play any role in shaping student educational outcomes as for 2012/2013.

Table 9 Effects of fatalities during the Second Intifada on school quality characteristics-school-level specification-OLS
(1)
(2)
(3)
(4)
(5)
(6)
(7)

Dep. var:: Equipment Materials Buildings Heating Classroom Technology PCA

\begin{tabular}{llllllll}
\hline Fatalities (in hundreds) & $\begin{array}{l}0.075 \\
(0.197)\end{array}$ & $\begin{array}{l}-0.066 \\
(0.199)\end{array}$ & $\begin{array}{l}0.009 \\
(0.255)\end{array}$ & $\begin{array}{l}-0.008 \\
(0.196)\end{array}$ & $(0.376)$ & $(0.170)$ & $(0.352)$ \\
& & & & & & & \\
& & & & & & & \\
& & & & & & \\
Mean of dep. var. & 1.490 & 1.643 & 2.061 & 2.592 & 2.592 & 2.071 & -0.0282 \\
SD of dep. var. & 0.966 & 0.987 & 1.217 & 1.063 & 1.063 & 0.922 & 1.482 \\
Observations & 98 & 98 & 98 & 98 & 98 & 98 & 98 \\
\hline
\end{tabular}

Standard errors are reported in parentheses and are clustered at the locality level. School-level specification. Each specification controls for an indicator for UNRWA versus public school, unemployment rate, poverty rate, the proportion of locality under area $\mathrm{C}$, the presence of the separation wall, type of locality (rural, urban or camp), average daily wage, the fraction of low-skilled workers and the fraction of Palestinian workers employed in Israel. In column (7) we use principal component analysis in order to combine the scores from these six questions into a more general index of school quality. *Significant at $10 \%$; **significant at $5 \%$; ***significant at $1 \%$ 
Table 10 Effects of family exposure to conflict on children's primary school GPA, adding control for fatalities after the Second Intifada

\begin{tabular}{|c|c|c|c|c|}
\hline & (1) & (2) & (3) & (4) \\
\hline Dep. var.: & 2SLS & 2SLS & Reduced form & Reduced form \\
\hline Family exposure to conflict & $\begin{array}{l}-6.464^{* * *} \\
(1.765)\end{array}$ & $\begin{array}{l}-7.359 * * \\
(3.583)\end{array}$ & & \\
\hline Fatalities during the 2nd Intifada (in hundreds) & & & $\begin{array}{l}-2.410^{* * *} \\
(0.680)\end{array}$ & $\begin{array}{l}-2.575^{*} \\
(1.340)\end{array}$ \\
\hline Fatalities after 2nd Intifada (in hundreds) & & $\begin{array}{l}1.650 \\
(5.621)\end{array}$ & & $\begin{array}{l}0.815 \\
(5.609)\end{array}$ \\
\hline First stage $F$ statistic & 55.45 & 17.84 & & \\
\hline Mean of dep. var. & 67.83 & 67.83 & 67.83 & 67.83 \\
\hline SD of dep. var. & 17.63 & 17.63 & 17.63 & 17.63 \\
\hline Observations & 4235 & 4235 & 4235 & 4235 \\
\hline
\end{tabular}

Standard errors are reported in parentheses and are clustered at the locality level. All regressions include individual-, school- and locality-level controls. Specifically, individual-level controls include gender of the child, gender of the household respondent, refugee status, dummies for children's and parental age, indicators for the father's and mother's educational level, a set of dummies for paternal employment status, as well as indicators for missing values in these covariates. The school-level control variable is an indicator for UNRWA versus public school. Locality-level variables contain unemployment rate, poverty rate, the proportion of locality under area $\mathrm{C}$, the presence of the separation wall, type of locality (rural, urban or camp), average daily wage, the fraction of low-skilled workers and the fraction of Palestinian workers employed in Israel. Columns (2) and (4) further include controls for fatalities after the conclusion of the Second Intifada. *Significant at 10\%; **significant at 5\%; ***significant at $1 \%$

In what follows, we present some heterogeneity analyses along several dimensions. We provide detailed regression results of these analyses in our Appendices A, B and C (see https://tinyurl.com/yb3v6tvh). First, we consider grade retention as an alternative outcome. Specifically, we exploit the fact that grade repetition in primary school occurs when students obtain a grade below 50 in at least 4 subjects. In case students fail up to 3 subjects, they sit for a make-up exam at the beginning of the next school year (MoEHE, 2015). Since our dataset provides information on student GPA not only for the school year 2012/2013 but also for the two preceding school years, i.e., 2010/2011 and 2011/2012, we constructed the outcome for grade retention using the three academic years, i.e., if the student failed to pass to the next grade in one of these three years. Results displayed in Table B.5 show that family exposure to conflict significantly increases the probability of grade retention by 14 percentage points. We obtain a similar result if we construct the outcome for grade repetition using the most recent school year, i.e., 2012/2013. 
Second, we estimate the models separately by student gender, by grade achieved distinguishing between elementary vs. middle schools, by paternal education, by number of siblings, household income and type of school (see Tables 19 and 20 in our Appendix B). The overall picture reveals that there are no significant differences between male and female students. At the same time, we detect no significant heterogeneous effects between elementary school (grades 1-6) and middle school (grades 7-10). Furthermore, we carry out the analysis after splitting the sample between more educated fathers (i.e., with an upper preparatory secondary education) and less educated fathers (i.e., with an education below upper preparatory secondary education). Although the difference is seemingly large, we cannot tell it apart from a statistical zero. Although our dataset does not contain information on household size, it does include information on the number of siblings in the household. We perform the analysis controlling for the number of siblings and splitting the sample by the median number of siblings. The 2SLS coefficient of interest is not sensitive to the inclusion of the number of siblings among the set of controls. Similarly, the estimated coefficient is similar when the sample is divided into the two groups. We conclude that the number of siblings leaves our main result substantially unchanged. In our dataset, household income is a categorical variable representing the net monthly income with the following categories measured by the local currency in Palestine "New Israeli Shekel" (NIS): (1) under NIS 1500; (2) NIS 1500-NIS 2499; (3) NIS 2500-NIS 3999; (4) NIS 4000-NIS 5000; (5) NIS 5000 and over. Reassuringly, theinclusion of household income among the set of the controls does not affect our main result. We also conduct heterogeneity analyses using an alternative definition of the dependent variable, i.e., an indicator taking value one (and zero otherwise) if the individual reported an income above the midpoint of the categories (i.e., 2500 and over). We find the effects to be concentrated among the household with income above the median. Finally, when we split the sample by school authority (public vs. UNRWA schools), we find that the effects are concentrated among the public schools.

\section{Potential mechanisms}

We now turn to the second part of our analysis: identification of potential mechanisms underlying the relationship between family exposure to conflict and primary school achievement of children. We hypothesize that exposure to conflict and violence in the early stages of a child's development may have long-term detrimental consequences on skills, both cognitive and non-cognitive, which in turn translate into worse school outcomes. Our hypothesis is related to a recent strand of the literature suggesting that non-cognitive skills have independent predictive power for a wide range of socioeconomic outcomes. For instance, Heckman et al. (2006) show that non-cognitive skills-which include personality traits-are important determinants of academic and economic success, and that their long-run effects seem comparable with the ones of cognitive skills. Currie and Stabile (2009) argue that non-cognitive skills are conceptually linked with mental health. They show that mental health problems in 
early childhood, in particular those associated with "externalizing" and "internalizing" behavior problems, have negative and persistent effects on future educational outcomes.

With our data, we are not able to identify the complete causal link between exposure to conflict and educational attainment, and decompose that link into separate paths via impaired cognitive and non-cognitive skills, respectively. However, we are able to study if - using the same identification strategy as before-exposure to conflict causally impacts cognitive and non-cognitive skills as mediating variables. Finding no effect of exposure to conflict on one of the mediators would rule out the pertinent candidate channel.

Before we report the results of 2SLS regressions with the mediators as dependent variables, we show that they have an "effect" on educational attainment at least in a descriptive sense. As regards cognitive ability, we consider the sub-scores for numerical, verbal and figural tests, as well as the total score obtained in the three tests; as concerns non-cognitive skills, we use the score for total strengths and difficulties (SDQ), the corresponding sub-scores for "internalizing" and "externalizing" behavioral problems, as well as the Big Five personality traits (i.e., openness, conscientiousness, extraversion, agreeableness and neuroticism).

Table 4 shows the results of OLS regressions of GPA on z-standardized measures of cognitive ability, scores for internalizing and externalizing problems, as well as the Big 5 personality dimensions. Column (1) shows the results of twelve separate regressions, where each mediating variable is included one at a time. As expected, cognitive ability is strongly related to GPA. Moreover, all measures of non-cognitive skills are significant predictors of GPA as well. Since the coefficients show the estimated association in terms of standard deviation changes, a comparison of the size of the coefficients illustrates the quantitative relevance of non-cognitive skills. For instance, externalizing problems and conscientiousness are about half as strong predictors as cognitive skills. ${ }^{22}$

Column (2) shows results when the cognitive ability sub-scores and the SDQ sub-scores are included jointly. We find that the influence of internalizing problems disappears almost completely. The coefficient on externalizing problems becomes smaller but remains strong. In column (3) we report the results when the Big 5 and cognitive ability are included jointly, and we find that conscientiousness remains the only personality trait with a sizeable association with GPA. Overall, cognitive and non-cognitive skills have independent "effects" on children's educational achievement. The most important non-cognitive skills are conscientiousness and (the absence) of externalizing, i.e., behavioral, problems.

To establish whether these variables lie on the causal path from exposure to conflict to GPA, we now estimate the same specification as in model (1) with children's

\footnotetext{
22 Notice that this only shows that the overall variation in GPA may be driven more by cognitive than by the measured non-cognitive skills. In what follows, we study whether the variation in GPA that is potentially affected by arguably exogenous exposure to conflict is driven more by conflict-induced changes in non-cognitive rather than cognitive skills.
} 
cognitive and non-cognitive skills as outcomes. We report the results of this analysis in Table 5. When examining cognitive ability (panel A), we do not find any significant effects, with the magnitude being close to zero for numeracy and positive coefficients for the figural and verbal tests. Hence, changes in cognitive ability do not seem to lie on the path from exposure to conflict to educational attainment. In contrast, the results for non-cognitive skills (panel B) reveal that family experience of conflict increases children's SDQ total score by 0.2 standard deviations. This coefficient masks heterogeneous effects between "internalizing" problems (column 2 ), where our coefficient of interest remains positive but the magnitude is substantially reduced, and "externalizing" behavior problems (column 3), for which we find a significant 0.25 standard deviations effect of family exposure to conflict. This evidence is in line with the results of Currie and Stabile (2006, 2009), who find that "externalizing" behavior problems are more likely to lead to negative outcomes than "internalizing" problems. We therefore believe that increased "externalizing" behavior problems may be one important channel through which exposure to conflict at least seven years in the past affects children's GPA today.

We now move to the examination of the Big Five personality traits (see columns 4 to 8 of panel B). Our main result is that parents' exposure to conflict during the Second Intifada reduces children's level of conscientiousness by 0.23 standard deviations. In light of the evidence reported in Table 4, this finding suggests another important channel, possibly related to the "externalizing" problems channel. Extraversion, agreeableness and neuroticism also seem to be affected by family exposure to conflict. However, as demonstrated in Table 4, these personality traits show no significant correlation with GPA, once cognitive skills and the other personality dimensions are controlled for. The remaining personality trait, openness, is instead not affected by the exposure to conflict. ${ }^{23}$

\section{Conclusion}

In this paper, we answer two related questions: does a family's exposure to violent political conflict affect the educational attainment of its children not only in the short- but also in the long-run? And if so, can we identify important channels that could be addressed to mitigate the adverse effects of political conflicts on educational outcomes?

Our paper contributes to the literature on long-run effects of early-childhood exposure to violence by exploring the role of cognitive and non-cognitive skill development as mechanism through which conflict exposure may affect educational attainment.

\footnotetext{
${ }^{23}$ In additional analyses, we have examined the role of other potential mechanisms whereby family exposure to conflict can affect children's education, such as, for instance, household income and religion. As shown in Table 16 in our Appendix B, we find no evidence of significant effects of family exposure to conflict on these mediators. Moreover, another complementary causal channel might be subjective life expectancy. In fact, children who experience violence or even death of relatives may anticipate a relatively early death, and may thus be less inclined to invest in education. Due to lack of data on subjective expectations, we are not able to test this idea directly.
} 
We provide new evidence that household exposure to conflict during the Second Intifada has long-term impacts on the human capital of students in the West Bank. Specifically, we examine the effect of house searches or occupations by the Israeli army between 2000 and 2005 on students' grade point averages in primary school (grades 5 to 9) in 2013.

Our identification strategy exploits the variation in the locality-level number of Palestinian fatalities during the Second Intifada as an arguably exogenous determinant of a family's exposure to conflict-related events. According to our estimates, one additional event reduces their children's GPA by approximately $35 \%$ of a standard deviation of the grade point average distribution. This result is quantitatively robust to a large number of specification changes. We also show that the effect of exposure to conflict is concentrated in the bottom and middle of the GPA distribution. In contrast, only small insignificant effects can be shown for the likelihood of being in the top quartile of the distribution.

As regards the potential mechanisms, we estimate the effect of exposure to violence on detailed measures of cognitive and non-cognitive skills. We find no effect of exposure on performance in a long and thorough cognitive skills (IQ) test. In contrast, important non-cognitive correlates of educational achievement, such as externalizing behavior problems and conscientiousness, appear to be affected. This result is in line with the findings on the effect of early education programs. For instance, with regard to the Perry Preschool Program, Heckman et al. (2013) conclude: "Although Perry did not produce long run gains in IQ, it did create persistent improvements in personality skills. The Perry program substantially improved externalizing behaviors (aggressive, antisocial, and rule-breaking behaviors)" (p. 2053). It almost appears as if exposure to conflict did the samewith a negative sign: although exposure is not detrimental to IQ, it leads to worse personality skills, which in turn affect educational attainment and other future outcomes.

Finally, in terms of policy recommendations, our paper suggests that children whose families have been exposed to conflict should be identified and invited to participate in interventions that are designed to improve social skills and self-control. Such interventions will likely lead to better educational attainment in school and possibly better labor market outcomes. When this is not possible during a conflict, children should be the main focus of interventions in the post-conflict recovery period.

Acknowledgments We thank the Editor, Shuaizhang Feng, and two anonymous referees for their helpful comments and suggestions. We are grateful to Ingrid Kubin, Olga Shemyakina, and participants at the 2016 SITES/IDEAs conference in Florence, the 2017 meeting of the Population Economics Section of the German Economic Association (VfS), the 2017 Population Association of America conference in Chicago, and the 2017 Royal Economic Society conference in Bristol for comments and suggestions. We are grateful to the Palestinian Ministry of Education and Higher Education, test administrators, and the students who participated in our study for their time and effort. All errors are our own.

Funding information Open Access funding provided by Università Cattolica del Sacro Cuore within the CRUI-CARE Agreement. The analysis presented in this paper is part of the project "Determinants of Cognitive Development in Deprived Environments: Evidence from the West Bank" funded by the German Research Foundation (DFG) under grant number JU 2769/2. 
Open Access This article is licensed under a Creative Commons Attribution 4.0 International License, which permits use, sharing, adaptation, distribution and reproduction in any medium or format, as long as you give appropriate credit to the original author(s) and the source, provide a link to the Creative Commons licence, and indicate if changes were made. The images or other third party material in this article are included in the article's Creative Commons licence, unless indicated otherwise in a credit line to the material. If material is not included in the article's Creative Commons licence and your intended use is not permitted by statutory regulation or exceeds the permitted use, you will need to obtain permission directly from the copyright holder. To view a copy of this licence, visit http://creativecommonshorg/licenses/by/4.0/.

\title{
Appendix A: Description of non-cognitive skills measures
}

Table 11 Strenghts and difficulties (SDQ) questionnaire

For each item, please mark the box for Not True, Somewhat True or Certainly True. It would help us if you answered all items as best as you can even if you are not absolutely certain or the item seems daft! Please give your answers on the basis of the child's behavior over the last six months.

Panel A: Internalizing problems
Emotional symptoms
...often complains of headaches, stomach-aches or sickness
Emotional symptoms
...worries or often seems worried
Emotional symptoms
...often fights with other children or bullies them
Emotional symptoms
...is nervous or clingy in new situations, easily loses confidence
Emotional symptoms
...fears, easily scared
Peer relationship problems
...is rather solitary, prefers to play alone
Peer relationship problems
...has at least one good friend
Peer relationship problems
...generally liked by other children
Peer relationship problems
...picked on or bullied by other children
Peer relationship problems
...gets along better with adults than with other children
Panel B: Externalizing problems
Conduct problems*
...often fights with other children
Conduct problems
...often loses temper
Conduct problems
...generally well behaved, usually does what adults request
Conduct problems
...often lies or cheats
Conduct problems
...steals from home, school or elsewhere
Hyperactivity/inattention
...restless, overactive, cannot stay still for long
Hyperactivity/inattention
...constantly fidgeting or squirming
Hyperactivity/inattention
...easily distracted, concentration wanders
Hyperactivity/inattention
...can stop and think things out before acting
Hyperactivity/inattention
...good attention span, sees work through to the end

\begin{abstract}
Notes: Parents were asked to state how much they agreed with each statement about their child on a 3-point scale ("Not true", "Somewhat true", "Certainly true"). Both internalizing and externalizing problems are defined on a 0 to 20 scale. The total score for SDQ is given by the sum of subscores for internalizing and externalizing problems (on a 0 to 40 scale), and does not include the prosocial behavior score (Goodman 1997). * This conduct problem was accidentally omitted of the instrument, i.e., the scale representing conduct problems consists only of four items and was scaled up to a maximum of 10
\end{abstract}


Table 12 Big-5 personality questionnaire (15 Item Version)

Below are some statements that may or may not describe what your child is like. For each statement, please indicate how much you agree or disagree that it describes your child. I see my child as someone who...

1. Is talkative

2. Does things carefully and completely

3. Is original, comes up with new ideas

4. Reserved; keeps thoughts and feelings to self

5. Has a forgiving nature

6. Worries a lot

7. Has an active imagination

8. Tends to be lazy

9. Likes artistic and creative experiences

10. Is considerate and kind to almost everyone

11. Does things efficiently (quickly and correctly)

12. Stays calm in tense situations

13. Is outgoing, sociable

14. Gets nervous easily

15. Is sometimes rude to others
(Dimension)

Extraversion

Concentiousness

Openness

Extraversion [-]

Agreeableness

Neuroticism

Openness

Concentiousness [-]

Openness

Agreeableness

Concentiousness

Neuroticism [-]

Extraversion

Neuroticism

Agreeableness [-]

Notes: Parents were asked to state how much they agreed with each statement on a 5-point Likert scale 


\section{Appendix B: Supplementary Figures and Tables}
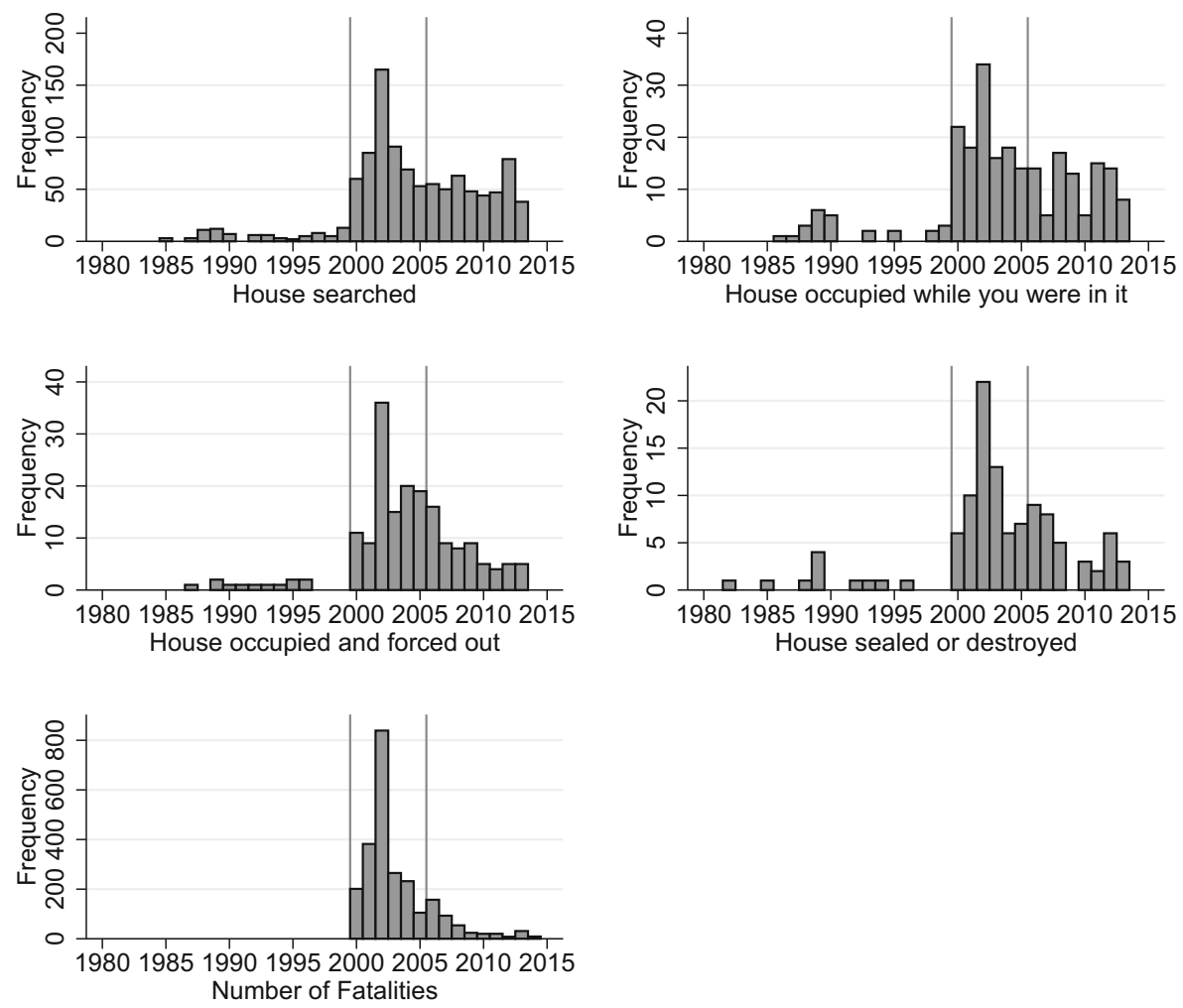

Fig. 3 Self-reported years of exposure to conflict and number of fatalities by year 


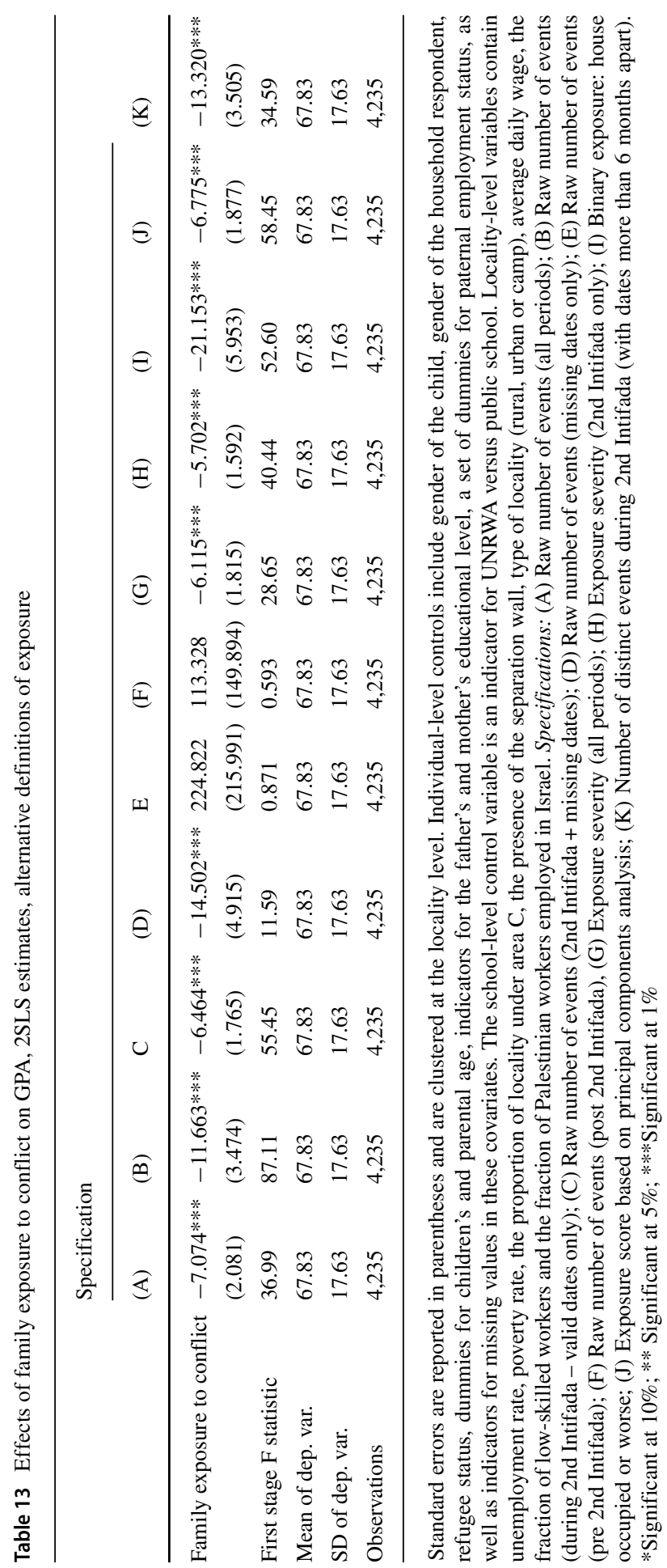




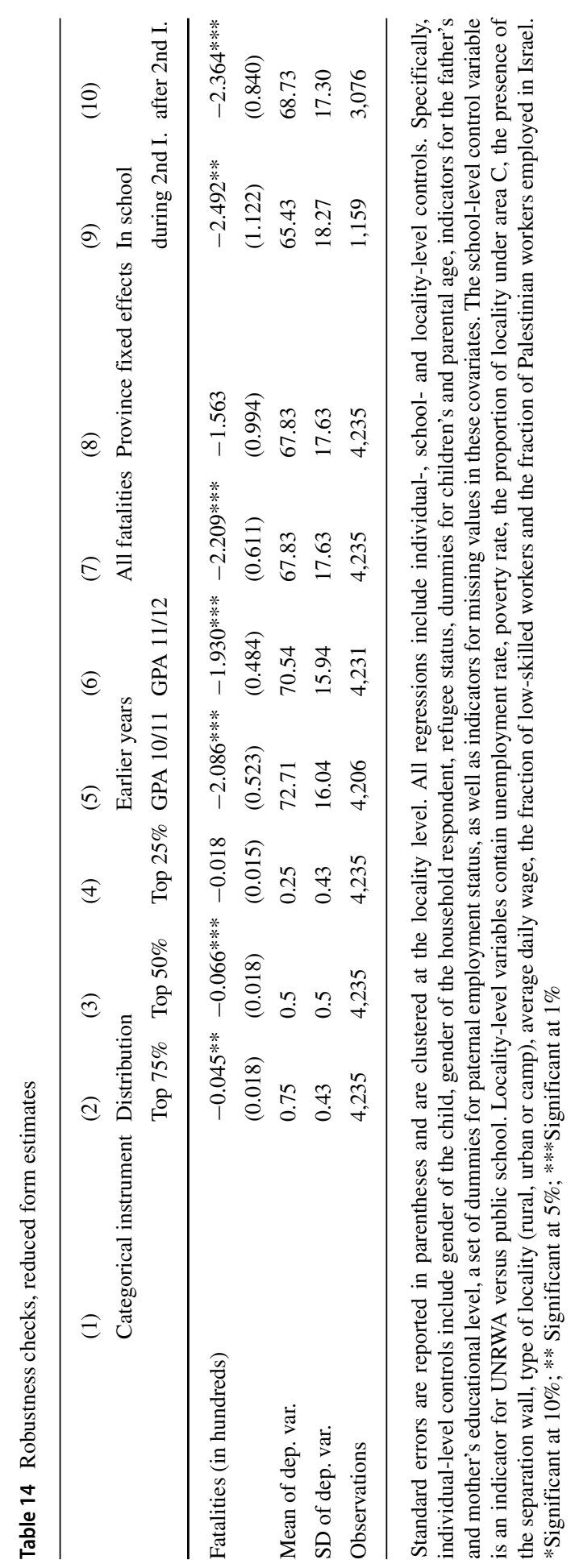




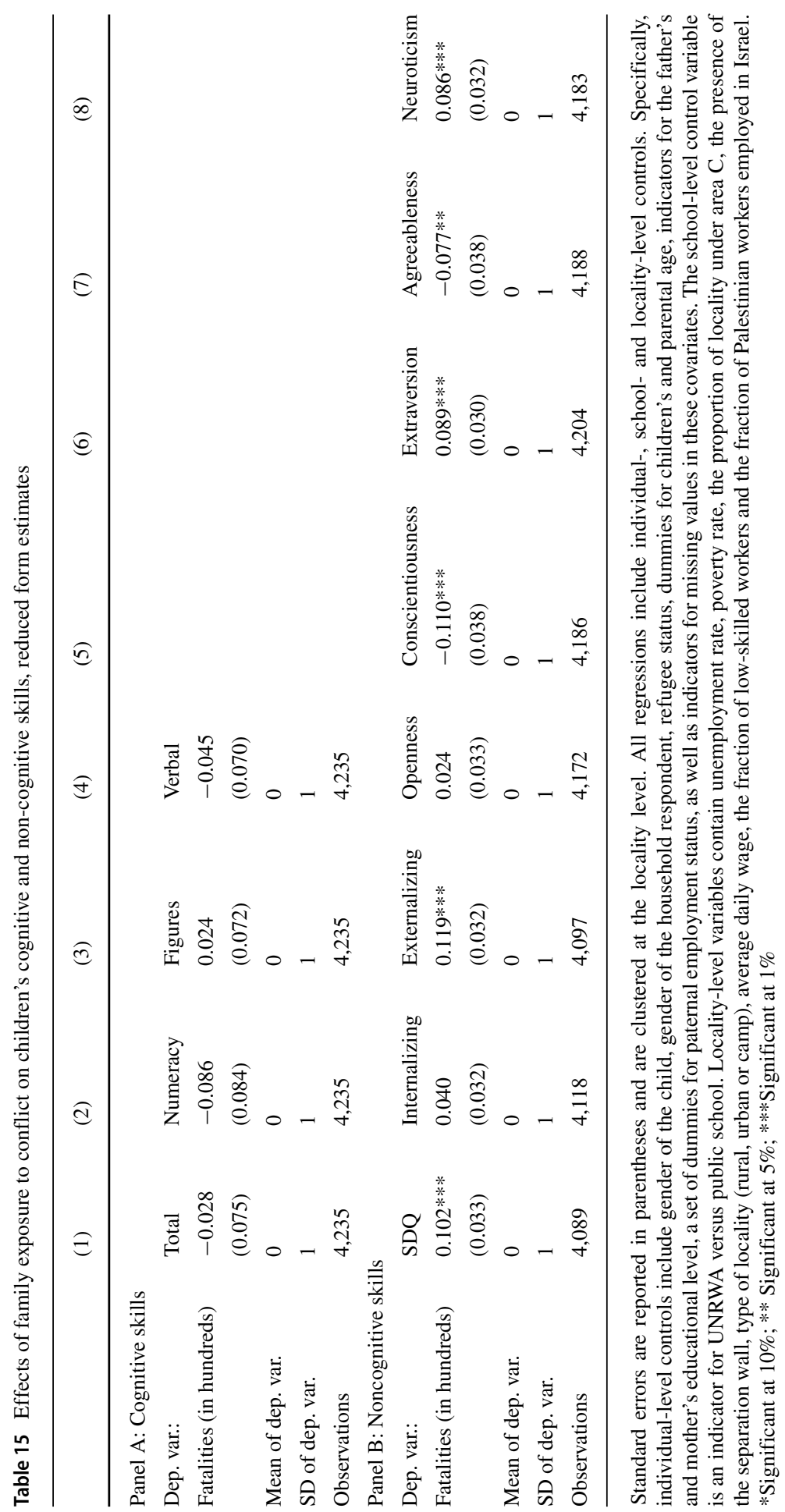


Table 16 Effects of family exposure to conflict on other potential mediators, 2SLS estimates

(1)

Dep. var.:

Family exposure to conflict

HH Income

$$
-0.048
$$

Grade in religion

First stage F statistic

Mean of dep. var.

SD of dep. var.

3,990
$-2.873$

4,235

Standard errors are reported in parentheses and are clustered at the locality level. All regressions include individual-, school- and locality-level controls. Specifically, individual-level controls include gender of the child, gender of the household respondent, refugee status, dummies for children's and parental age, indicators for the father's and mother's educational level, a set of dummies for paternal employment status, as well as indicators for missing values in these covariates. The school-level control variable is an indicator for UNRWA versus public school. Locality-level variables contain unemployment rate, poverty rate, the proportion of locality under area $\mathrm{C}$, the presence of the separation wall, type of locality (rural, urban or camp), average daily wage, the fraction of low-skilled workers and the fraction of Palestinian workers employed in Israel. *Significant at $10 \%$; * Significant at 5\%; ***Significant at $1 \%$

Table 17 Effects of family exposure to conflict on children's grade retention

(1)

OLS
(2)

Reduced form
(3)

2SLS

Dep. var.:

Grade retention Grade retention Family exposure to conflict Grade retention

Family exposure to conflict $0.020 * * *$

(0.006)

Fatalities (in hundreds)

First stage F statistic

Mean of dep. var.

SD of dep. var.

Observations
$0.143^{* * *}$

(0.047)

$\begin{array}{ll}0.053 * * * & 0.373 * * * \\ (0.019) & (0.050)\end{array}$

55.5 55.5

0.107

Standard errors are reported in parentheses and are clustered at the locality level. All regressions include individual-, school- and locality-level controls. Specifically, individual-level controls include gender of the child, gender of the household respondent, refugee status, dummies for children's and parental age, indicators for the father's and mother's educational level, a set of dummies for paternal employment status, as well as indicators for missing values in these covariates. The school-level control variable is an indicator for UNRWA versus public school. Locality-level variables contain unemployment rate, poverty rate, the proportion of locality under area $\mathrm{C}$, the presence of the separation wall, type of locality (rural, urban or camp), average daily wage, the fraction of low-skilled workers and the fraction of Palestinian workers employed in Israel. *Significant at 10\%; ** Significant at 5\%; ***Significant at $1 \%$ 


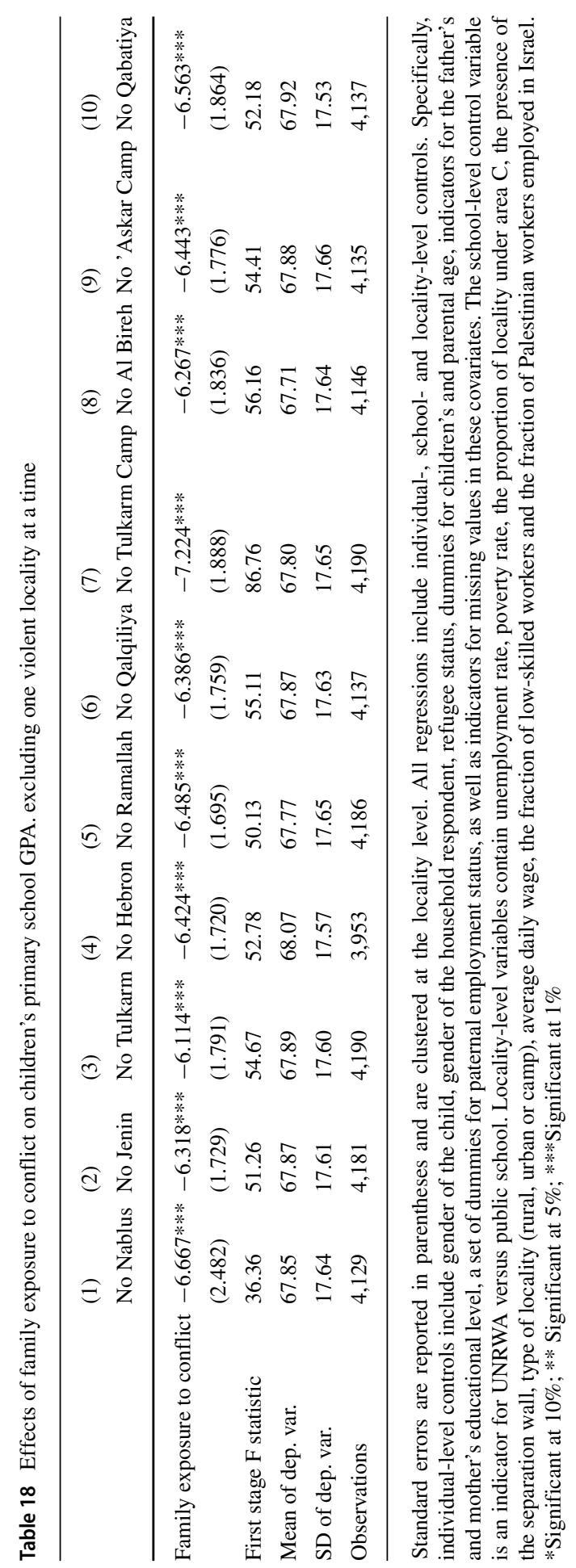


Table 19 Effects of family exposure to conflict on children's primary school GPA, by gender and grade achieved
(1)
(2)
(3)
(4)
(5)

\begin{tabular}{llllll} 
Sample: & All & Females & Males & Elementary school & Middle school \\
\hline Family exposure to conflict & $-6.464 * * *$ & $-11.889^{* * *}$ & -9.740 & $-7.679 * * *$ & $-5.950^{* * *}$ \\
& $(1.765)$ & $(2.928)$ & $(6.409)$ & $(2.656)$ & $(2.290)$ \\
First stage F statistic & 55.45 & 29.72 & 12.01 & 81.52 & 22.40 \\
Mean of dep. var. & 67.83 & 68.79 & 65.58 & 68.96 & 67.08 \\
SD of dep. var. & 17.63 & 17.66 & 17.37 & 17.65 & 17.59 \\
Observations & 4,235 & 2,967 & 1,268 & 1,693 & 2,542
\end{tabular}

Standard errors are reported in parentheses and are clustered at the locality level. All regressions include individual-, school- and locality-level controls. Specifically, individual-level controls include gender of the child, gender of the household respondent, refugee status, dummies for children's and parental age, indicators for the father's and mother's educational level, a set of dummies for paternal employment status, as well as indicators for missing values in these covariates. The school-level control variable is an indicator for UNRWA versus public school. Locality-level variables contain unemployment rate, poverty rate, the proportion of locality under area $\mathrm{C}$, the presence of the separation wall, type of locality (rural, urban or camp), average daily wage, the fraction of low-skilled workers and the fraction of Palestinian workers employed in Israel. *Significant at 10\%; ** Significant at 5\%; ***Significant at $1 \%$ 


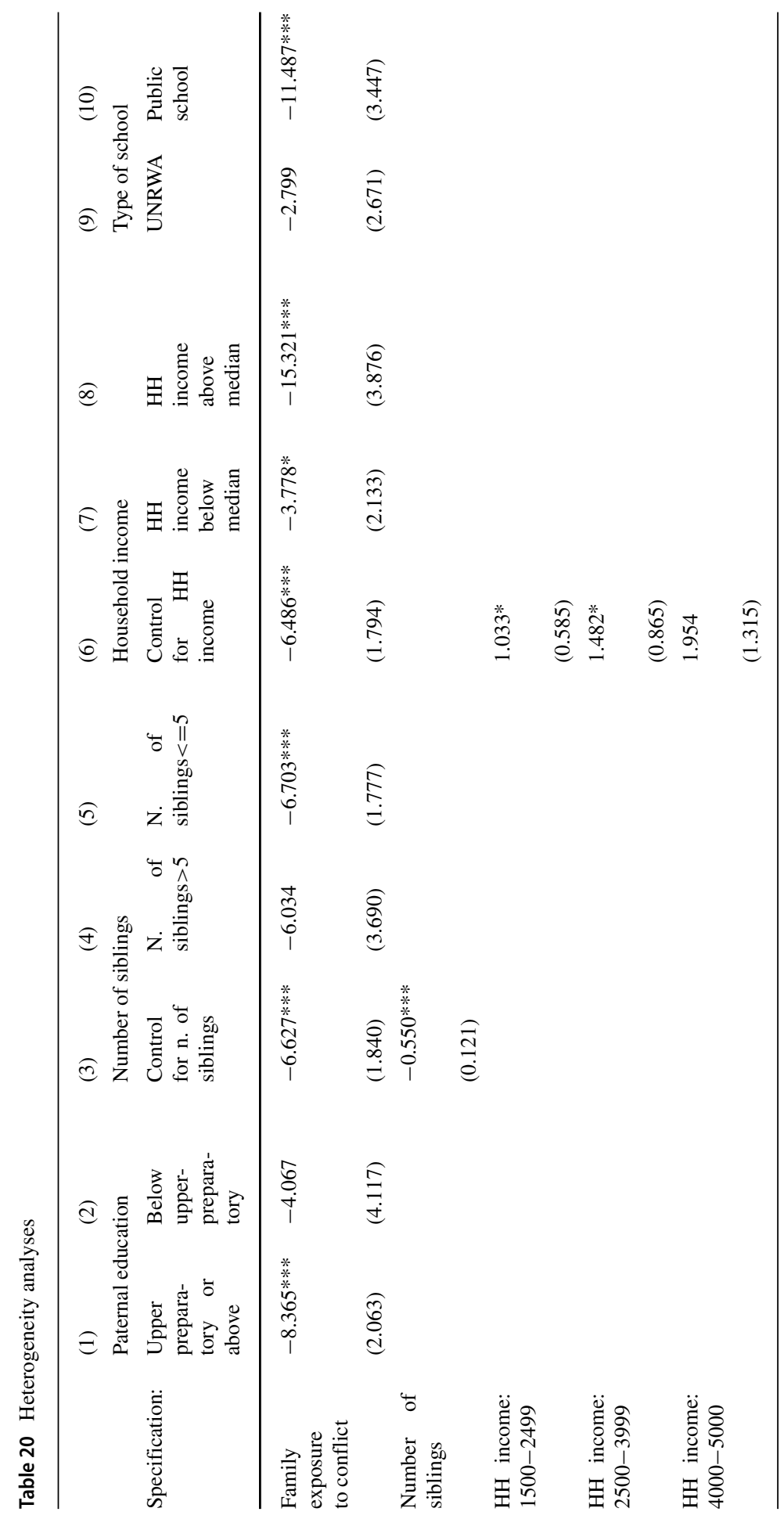




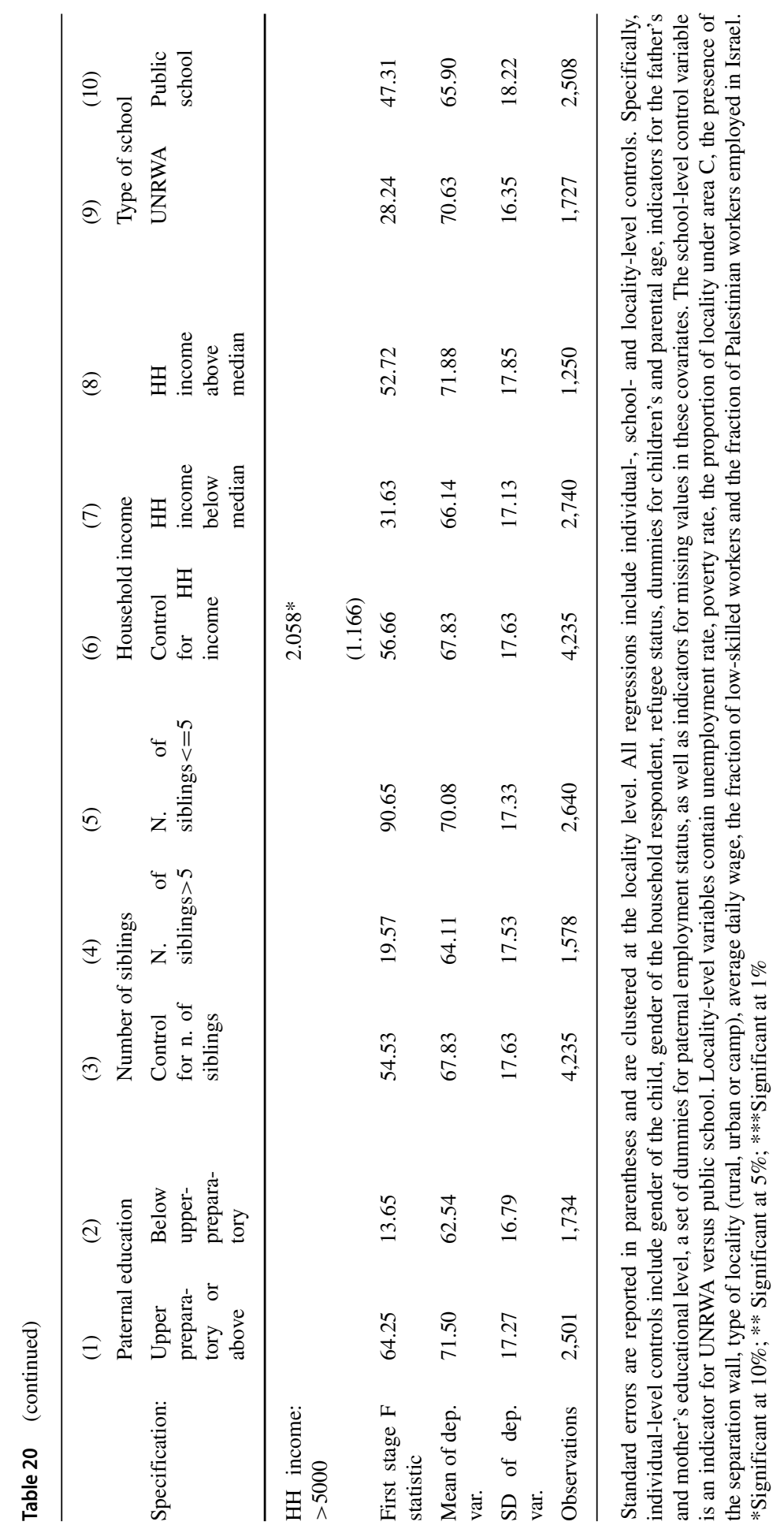




\section{Appendix C: Sample Design}

\section{C.1 Study population}

The study population consisted of all students in Palestinian schools, which:

- were located in the northern provinces of Palestinian areas (the West Bank).

- were either governmental or UNRWA schools. Private schools were not included in the study population.

- included each of grades 5 to 9 . Schools that were missing one of these grade levels were excluded from the study population.

- were either for "boys only" or "girls only". Gender mixed schools were not included in the study population.

The school was the basis for selecting the sampled students. Both UNRWA and governmental schools in the West Bank were classified in directorates for the different regions as the following:

- The North region includes the following governmental directorates: Jenin, Qabatya, Tubas, Nablus, south of Nablus, Tulkarem, Qalqilya and Salfit. According to the UNRWA division, this is the Nablus area.

- The Central region includes the following governmental directorates: Ramallah, the outskirts of Jerusalem, Jerusalem, Jericho. According to the UNRWA division, this is the Jerusalem area.

- The South region includes the following governmental directorates: Hebron, South Hebron, north of Hebron, and Bethlehem. According to the UNRWA division, this is the Hebron area.

\section{C.2 The study sample}

The sample has been selected according to the following requirements:

- Selection of 100 schools to participate in the study: 60 governmental schools and 40 UNRWA schools

- The sampled schools were selected by stratified random sample. Thus, the schools were selected at random from the three regions (North, Center and South) according to the proportion of schools in each region.

- Selection of 60 student (girls or boys) from each school: 12 students from each grade level (5 to 9 ) were randomly selected (based on school records). Thus, the size of the sample of students is 6,000 .

\section{References}

Akbulut-Yuksel M (2014) Children of war: the long-run effects of large-scale physical destruction and warfare on children. J Hum Resour 49(3):634-662

Akresh R, De Walque D (2008) Armed conflict and schooling: evidence from the 1994 Rwandan genocide. World Bank Policy Research Working Paper Series 
Akresh R, Lucchetti L, Thirumurthy H (2012) Wars and child health: evidence from the Eritrean-Ethiopian conflict. Journal of Development Economics 99(2):330-340

Amodio F, Di Maio M (2017) Making do with what you have: conflict, input misallocation and firm performance. Econ J 128(615):2559-2612

Arcand Jss-L, Wouabe ED (2009) Households in a time of war: instrumental variables evidence for angola. Geneva working paper, The Graduate Institute, Geneva

Barenbaum NB, Winter DG (2008) History of modern personality theory and research. In: John OP, Robins RW, Pervin LA (eds) Handbook of personality: theory and research. Guilford Press, New York

Bertoni E, Di Maio M, Molini V, Nisticò R (2019) Education is forbidden: the effect of the Boko Haram conflict on education in North-East Nigeria. J Dev Econ 141:102249

Blattman C, Annan J (2010) The consequences of child soldiering. Review of Economics and Statistics 92(4):882-898

Borofsky LA, Kellerman I, Baucom B, Oliver PH, Margolin G (2013) Community violence exposure and adolescents' school engagement and academic achievement over time. Psychology of Violence 3(4):381

Brück T, Di Maio M, Miaari SH (2019) Learning the hard way: the effect of violent conflict on student academic achievement. J Eur Econ Assoc 17(5):1502-1537

B'Tselem (2002) Operation defensive shield, soldiers testimonies, Palestinian testimonies. Technical report, B'Tselem: The Israeli Information Center for Human Rights in the Occupied Territories, Jerusalem

Calì M, Miaari S (2013) The labor market impact of mobility restrictions: evidence from the west bank. Technical Report 6457, World Bank Policy Research Working Paper

Calì M, Miaari SH (2015) Trade, employment and conflict: evidence from the Second Intifada

Calì M, Miaari SH (2018) The labor market impact of mobility restrictions: evidence from the West Bank. Labour Economics 51:136-151

Cattell RB, Cattell AKS (1965) Culture fair intelligence test: scale 2. Institute for Personality and Ability Testing, Champaign

Chamarbagwala R, Morán HE (2011) The human capital consequences of civil war: evidence from guatemala. J Dev Econ 94(1):41-61

Conti G, Heckman J (2012) The economics of child well-being. IZA Discussion Papers 6930, Institute for the Study of Labor (IZA)

Currie J (2001) Early childhood education programs. J Econ Perspect 15:213-238

Currie J, Stabile M (2006) Child mental health and human capital accumulation: the case of ADHD. Journal of Health Economics 25(6):1094-1118

Currie J, Stabile M (2009) Mental health in childhood and human capital. In: Gruber J (ed) The problems of disadvantaged youth: an economic perspective, pp 115-148. University of Chicago Press

Di Maio M, Nandi TK (2013) The effect of the Israeli-Palestinian conflict on child labor and school attendance in the West Bank. Journal of Development Economics 100(1):107-116

Di Maio M, Nisticò R (2019) The effect of parental job loss on child school dropout: evidence from the occupied Palestinian territories. J Dev Econ 141:102375

Eckstein Z, Tsiddon D (2004) Macroeconomic consequences of terror: theory and the case of Israel. J Monet Econ 51(5):971-1002

Fallah B, Saad A (1227) Schooling choices' responses to labor market shocks: evidence from a natural experiment Economic Research Forum Working Papers

Goldberg L (1993) The structure of phenotypic personality traits. Am Psychol 48(1):26-34

Goodman R (1997) The strengths and difficulties questionnaire: a research note. Journal of Child Psychology and Psychiatry 38(5):581-586

Goodman R, Ford T, Simmons H, Gatward R, Meltzer H (2000) Using the Strengths and Difficulties Questionnaire (SDQ) to screen for child psychiatric disorders in a community sample. British Journal of Psychiatry 177(6):534-539

Gould ED, Lavy V, Paserman MD (2011) Sixty years after the magic carpet ride: the long-run effect of the early childhood environment on social and economic outcomes. Review of Economic Studies 78:938-973

Heckman J (2000) Policies to foster human capital. Res Econ 54:3-56

Heckman J, Kautz T (2012) Hard evidence on soft skills. Labour Econ 19:451-464

Heckman J, Pinto R, Savelyev P (2013) Understanding the mechanisms through which an influential early childhood program boosted adult outcomes. Am Econ Rev 103(6):2052-86 
Heckman J, Stixrud J, Urzua S (2006) The effects of cognitive and noncognitive abilities on labor market outcomes and social behavior. J Labor Econ 24(3):411-482

Jaeger D, Paserman M (2008) The cycle of violence? An empirical analysis of fatalities in the PalestinianIsraeli Conflict. American Economic Review 98(3):1591-1604

Jaeger DA, Klor EF, Miaari SH, Paserman MD (2012) The struggle for Palestinian hearts and minds:, violence and public opinion in the Second Intifada. Journal of Public Economics 96(3-4):354-368

Justino P, Leone M, Salardi P (2013) Short-and long-term impact of violence on education: the case of timor leste. The World Bank Economic Review 28(2):320-353

Kaestner R, Callison K (2011) Adolescent cognitive and noncognitive correlates of adult health. J Hum Cap 5(1):29-69

Krueger AB, Whitmore DM (2001) The effect of attending a small class in the early grades on college-test taking and middle school test results: evidence from project star. Economic Journal 111:1-28

León G (2012) Civil conflict and human capital accumulation: the long-term effects of political violence in perú. J Hum Resour 47(4):991-1022

Mansour H, Rees DI (2012) Armed conflict and birth weight: evidence from the al-Aqsa Intifada. Journal of Development Economics 99(1):190-199

Miaari S, Zussman A, Zussman N (2012) Employment restrictions and political violence in the IsraeliPalestinian conflict. Economics of Security Working Paper

Miaari SH, Sauer RM (2011) The labor market costs of conflict: closures, foreign workers, and Palestinian employment and earnings. Rev Econ Househ 9(1):129-148

Minoiu C, Shemyakina ON (2014) Armed conflict, household victimization, and child health in Cote d'Ivoire. Journal of Development Economics 108:237-255

MoEHE (2012) Educational statistical year book 2012/2011. Technical report

Ortar G, Shachor A (1980) MILTA: A battery of tests for ages 9 through 18. Ministry of Education and Culture, Hebrew

Osofsky JD (1995) The effects of exposure to violence on young children. Am Psychol 50:782-788

PCBS (2010) Migration survey in the Palestinian territory. Technical report Palestinian Central Bureau of Statistics, Ramallah

PCBS (2013) Children of Palestine-issues and statistics (in Arabic). child chain statistics. Technical report Palestinian Central Bureau of Statistics, Ramallah

Pivovarova M, Swee EL (2015) Quantifying the microeconomic effects of war using panel data: evidence from nepal. World Dev 66:308-321

Raven JC (1983) The standard progressive matrices, 1938-83. Psychological Corporation, New York

Schwartz D, Gorman AH (2003) Community violence exposure and children's academic functioning. J Educ Psychol 95(1):163

Shemyakina O (2011) The effect of armed conflict on accumulation of schooling: results from Tajikistan. Journal of Development Economics 95(2):186-200

Thorndike RL, Hagen E (1971) Cognitive abilities test, form 1, levels A-H, grades 3-12. Houghton Mifflin, Boston

UNESCO (2011) World data on education, 7'th edition 2010/11. Technical report. United Nation Educational Scientific and Cultural Organization, Paris

UNRWA (2007) Emergency call. Technical report

UNSCO (2014) Report to the ad hoc liaison committee New York 22 September 2014, Technical report, Office of the United Nations Special Coordinator for the Middle East Peace Process

Verwimp P, Van Bavel J (2013) Schooling, violent conflict, and gender in Burundi. The World Bank Economic Review 28(2):384-411

Vishwanath T, Blankespoor B, Calandra F, Krishnan N, Mahadevan M, Yoshida M (2014) Seeing believes: poverty in the Palestinian territories. Technical report World Bank Group, Washington

Publisher's note Springer Nature remains neutral with regard to jurisdictional claims in published maps and institutional affiliations. 